\title{
Applications of Open Channel Membrane Modules to Treat and Reuse Wastewater
}

\author{
A. Pervov* and N. Matveev
}

Department of Water Supply, Moscow State University of Civil Engineering, Russian Federation

\begin{abstract}
Local utilities often face problems of domestic wastewater, local industrial wastes, storm water disposal due to existing strict regulations. For many local industries, the problem of wastewater treatment and discharge into surface reservoirs can't be solved through the use of conventional biological treatment techniques. Current discharge standards require very strict removal of a number of impurities such as ammonia, nitrates, phosphate, etc. To reach this level of removal, modern modified biological treatment facilities (membrane bioreactors etc.) are used.
\end{abstract}

This article suggests a new technical approach to treat directly domestic wastewater and storm water to completely reuse them for technical needs.

The modern concept of rational water resources management requires the development of new efficient techniques that provide wastewater treatment and reuse.

As RO membranes simultaneously reject all dissolved impurities such as BOD, TDS, ammonia, phosphates etc., they become very attractive for the direct treatment of wastewater without biological stage. To treat wastewater, specially designed membrane "open channel" modules are used that do not possess "dead areas" that cause fouling or require pretreatment. A solution to $\mathrm{RO}$ concentrate disposal problem is presented that consists of reducing of initial wastewater volume by 100 times. Concentrate is withdrawn from membrane unit as sludge moisture. The efficient use of membrane $\mathrm{RO}$ techniques is connected with a salt balance in water system. Thus, to provide high ecological efficiency of developed techniques, all components of water supply and wastewater discharge systems should be accounted for.

Keywords: Reverse osmosis, open channel membrane module, wastewater reuse, domestic wastewater, storm water, ammonia reduction, oil reduction, car wash effluents.

\section{INTRODUCTION: USING MEMBRANES TO TREAT WASTEWATER}

At early stages of wastewater treatment with the use of membranes, the role of the membrane was limited to "supporting" conventional biological treatment by reducing suspended matter and activated sludge, and to post-treating biologically treated wastewater.

Meanwhile, high rejection qualities of membranes enable us to treat sewage directly without biological treatment process to obtain high quality water. Such approach to use membranes substantially reduces costs and simplifies treatment techniques.

Membrane bioreactor (MBR) is becoming popular and efficient tool to reduce volume of water treatment plant and provide better quality of treated water with lower BOD, complete nitrification and partial nitrogen removal [1]. Today submerged membranes (flat sheet or capillary) are mainly used at MBR applications and provide stable operation due to application of backwashes and chemical cleanings.

Initially MBR process used cross flow membrane operational mode where high velocities reduced

*Address correspondence to this author at the Department of Water Supply, Moscow State University of Civil Engineering, Russian Federation; Tel/Fax: +7495 766-7644; E-mail: ale-pervov@yandex.ru concentration polarization and fouling [2]. High cross flow velocities require higher energy consumption than dead-end filtration mode used in submerged MBR process.

Biological treatment process does not provide required removal level for major contaminants to reclaim to reclaim municipal effluents, thus $\mathrm{RO}$ desalination techniques could be successfully applied to post-treat biologically used wastewater. The concept of converting wastewater into new, raw water supply for further treatment to potable standards is called "indirect potable reuse", and is in use in the U.S. since the 1970s [3].

As membranes demonstrate high rejection characteristics for different contaminants, the idea to use membranes [4,5] and other techniques $[6,7]$ for direct treatment of domestic and urban effluents promise to significantly reduce costs and simplify treatment. Table $\mathbf{1}$ demonstrates $\mathrm{RO}$ rejection characteristics for main municipal wastewater ingredients [6,7]. Figure 2 shows a schematic flow diagram of direct wastewater treatment by $\mathrm{RO}$, using pretreatment.

Biological water treatment does not always ensure high quality of purified water to efficiently reuse it for technical and domestic purposes. To provide efficient reduction of TDS, organics, nitrates, phosphates, etc., 
Table 1: Municipal Wastewater Treatment with Different RO Pretreatment Stages

\begin{tabular}{|c|c|c|c|c|c|c|c|c|c|}
\hline \multirow[b]{2}{*}{ Parameters } & \multicolumn{3}{|c|}{$\begin{array}{c}\text { Direct RO treatment microfiltration } \\
\text { pretreatment }\end{array}$} & \multicolumn{3}{|c|}{$\begin{array}{c}\text { Direct RO treatment sand filter } \\
\text { pretreatment }\end{array}$} & \multicolumn{3}{|c|}{$\begin{array}{l}\text { RO treatment after } \\
\text { MBR }\end{array}$} \\
\hline & wastewater & $\begin{array}{c}\text { Effluent } \\
\text { microfiltration } \\
\text { pretreatment }\end{array}$ & $\begin{array}{l}\text { Direct } \\
\text { RO }\end{array}$ & Effluent & $\begin{array}{c}\text { After } \\
\text { pretreatment/sa } \\
\text { nd filter }\end{array}$ & $\begin{array}{l}\text { After } \\
\text { RO }\end{array}$ & Feed & MBR & RO \\
\hline $\mathrm{pH}$ & - & 5.4 & 5 & 7.06 & 6.99 & 5.92 & 7.4 & 7.27 & 6.01 \\
\hline $\begin{array}{l}\text { Total dissolved solids, } \\
\text { mg/l }\end{array}$ & 2030 & 2030 & 99 & 994 & 968 & 12.78 & 1100 & 999 & 51 \\
\hline Turbidity, NTU & 15 & $<1$ & 0 & 23.54 & 7.33 & 0.14 & - & 0.18 & 0.07 \\
\hline Ammonia $\left(\mathrm{NH}_{4}\right), \mathrm{mg} / \mathrm{l}$ & - & 38 & 3,6 & 18.78 & 18.19 & 1.55 & 27 & 0.11 & - \\
\hline Nitrates $\left(\mathrm{NO}_{3}\right), \mathrm{mg} / \mathrm{l}$ & 40 & 39 & 7,1 & 3.47 & 2.42 & 1.08 & - & - & - \\
\hline Phosphates $\left(\mathrm{PO}_{4}\right), \mathrm{mg} / \mathrm{l}$ & 56 & 54 & 3,8 & 7.97 & 6.08 & 0.67 & 24 & 1.46 & - \\
\hline $\begin{array}{l}\text { Total coliforms } \\
\text { (colonies } / 100 \mathrm{ml} \text { ) }\end{array}$ & $3.5 \cdot 10^{6}$ & absence & $\begin{array}{l}\text { absenc } \\
\mathrm{e}\end{array}$ & 700 & 200 & - & - & - & - \\
\hline BOD5, mg/l & 32 & 3 & $<0.5$ & 9.3 & 3,2 & 1.2 & 268 & 1.05 & - \\
\hline $\mathrm{COD}, \mathrm{mg} / \mathrm{l}$ & 118 & 74 & 15 & 42.73 & 26.07 & 13.47 & 530 & 14.5 & - \\
\hline TOC, mg/l & 30 & 21 & 1.9 & - & - & - & - & 6.18 & $<0.5$ \\
\hline
\end{tabular}

reverse osmosis desalination techniques are implemented to post treat wastewater after biological treatment. As $\mathrm{RO}$ feed water should be adequately pretreated to avoid membrane fouling and scaling, the use of membrane bioreactor facilities is required to treat wastewater (Figure 1).

Ultrafiltration submerged membranes (membrane cassettes tailored with flat-sheet or capillary membranes) are used for adequate pretreatment of biologically treated wastewater. Product water is collected in the tank for further $\mathrm{RO}$ desalination, acid and antiscalant solutions are injected in feed water tank to control scaling in membrane modules.

Due to low costs, high efficiency and low energy and reagent consumption, reverse osmosis membranes have become attractive to engineers as a replacement to conventional wastewater treatment techniques. Depending on wastewater composition and classes of contaminants requiring removal, ultrafiltration, nanofiltration, or reverse osmosis

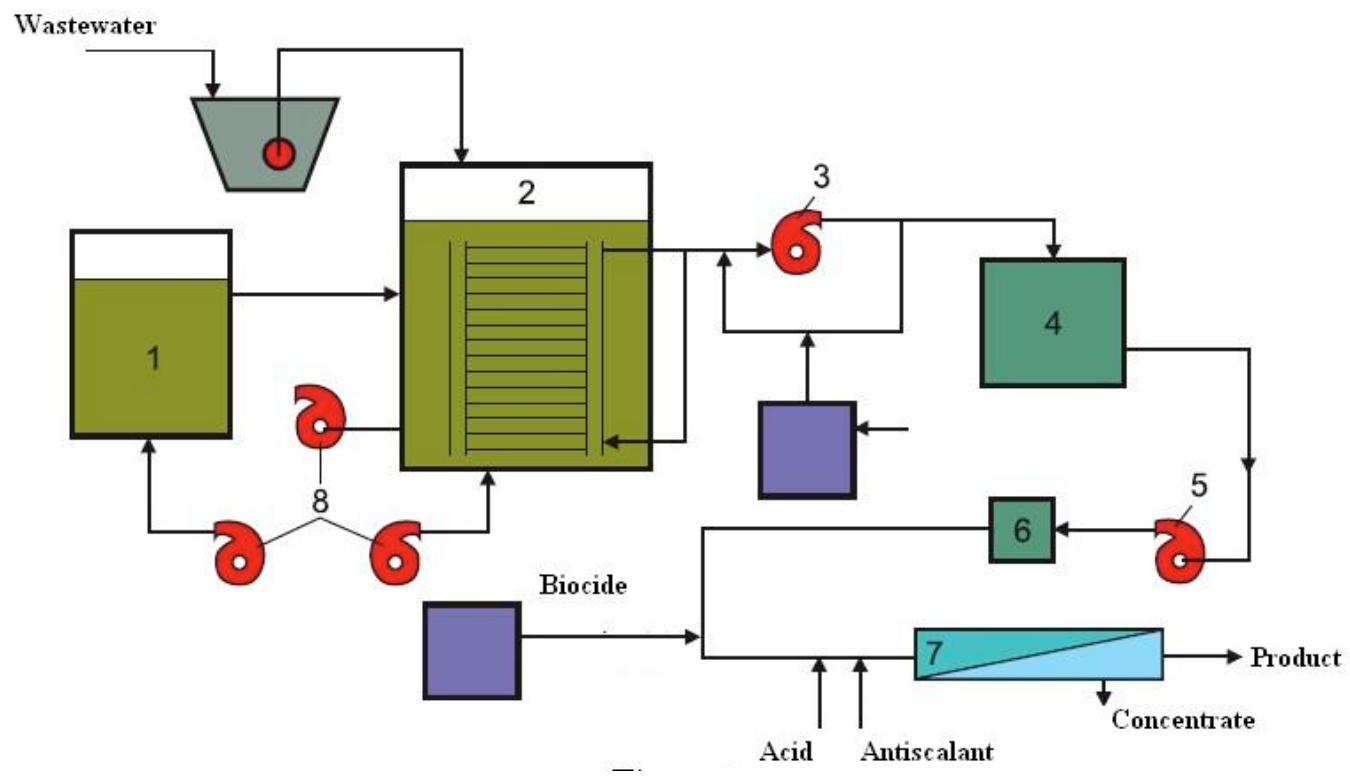

Figure 1: 1 - activated sludge tank, 2 - membrane bioreactor, 3 - vacuum-pump, 4 - product tank, 5 - high pressure pump, 6 cartridge filter, 7 - reverse osmosis module, 8 - air pumps. 


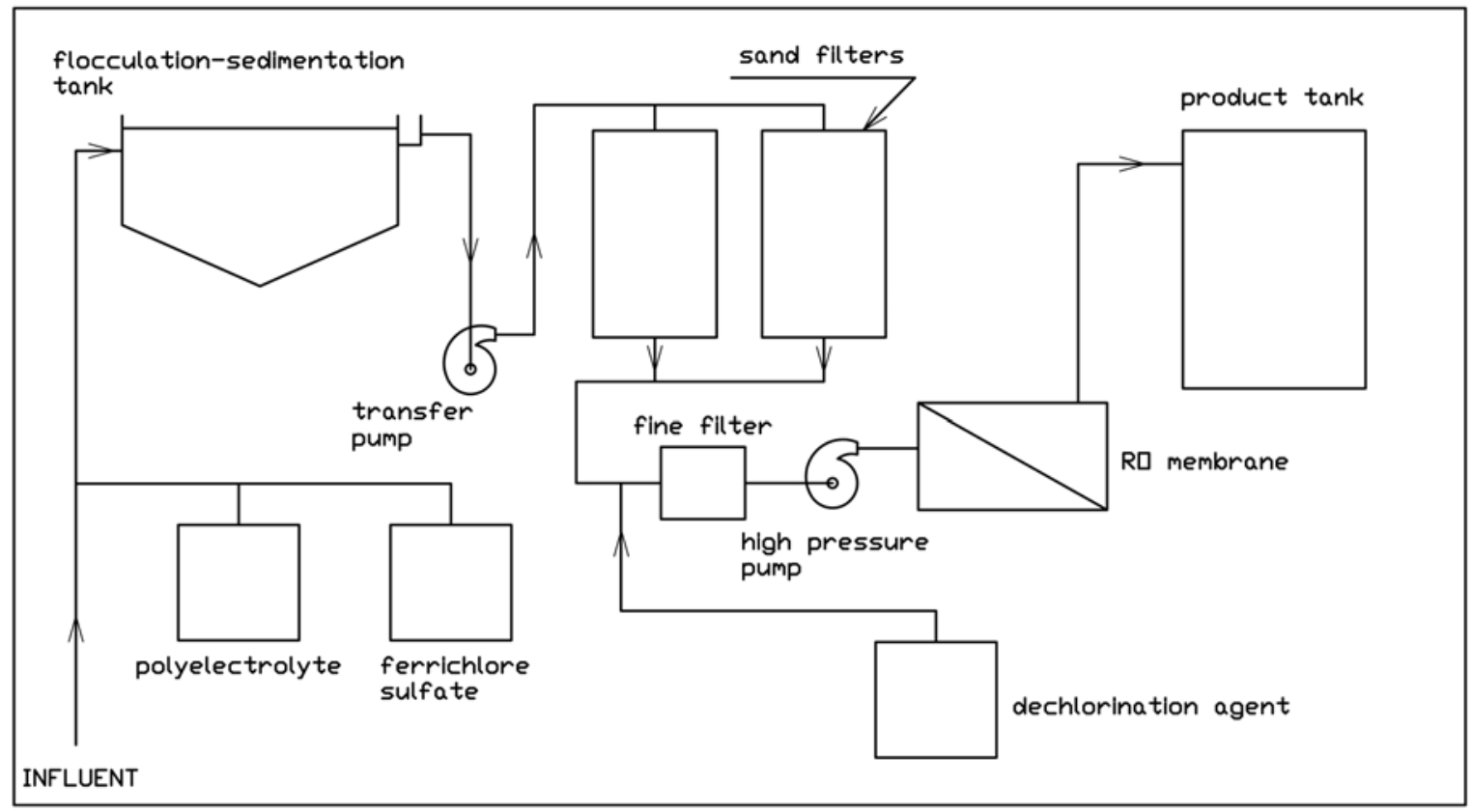

Figure 2: Advanced pretreatment and RO desalination system (direct membrane separation, $\mathrm{RO}$ ).

techniques can be introduced into wastewater treatment practices to improve water quality and reuse water for agricultural, industrial, and domestic applications.

As it was already discussed, high rejection characteristics of RO membranes enable us to treat sewage directly and obtain high-quality water without application of biological processes. This approach to using membrane tools substantially reduces costs and simplifies treatment techniques. However, the main disadvantages of commercially available $\mathrm{RO}$ facilities are attributed to high fouling propensities, high cost pretreatment requirements, and concentrate disposal problems.

To overcome these problems, a series of experimental investigations was performed to develop newly modified "open channel" modules that possess a limited scaling and fouling potential.

For a long time formation of colloidal fouling layers on RO membranes was attributed to hydrodynamic flow characteristics (such as cross-flow velocities, concentration polarization level etc.).

It was also reported that configuration of membrane channel and module also should be considered as decisive factor that influence fouling [11].

There are examples in water treatment practice that directly treat surface water with nanofiltration membranes without pretreatment $[12,13]$.
As reported [13], the process efficiency and reliabilities attributed mainly to hydraulic flow conditions in the membrane channels that provide enough shear force for the particles not to foul the membrane. These conditions are provided by channel configuration (using tubular or capillary membranes), by high cross-flow velocities as well as through application of hydraulic flushes and chemical cleanings.

This paper presents results of research that was conducted to improve conventional spiral wound configuration to treat directly wastewater, the conclusion that membrane fouling is dependent not only on hydraulic factors but on channel configuration as well was claimed in publication as early as 1991 [8] and this led to re-evaluation of the layout of the spiral wound module.

The main disadvantages of spiral wound module are attributed to presence of separation spacer mesh in the feed channel as it traps fouling particles and increases flow resistance (Figure 3). The places (spots) where mesh contacts membrane surface provide "dead areas" without cross-flow, thus resulting in high concentration increase at the membrane surface within this area. Concentration polarization increases and initiates formation of crystals and coagulation of colloids inside these "dead areas".

Elimination of the mesh could help to develop new types of modules with decreased fouling potential. This idea was discussed by Richard Riddle [10] in a report 


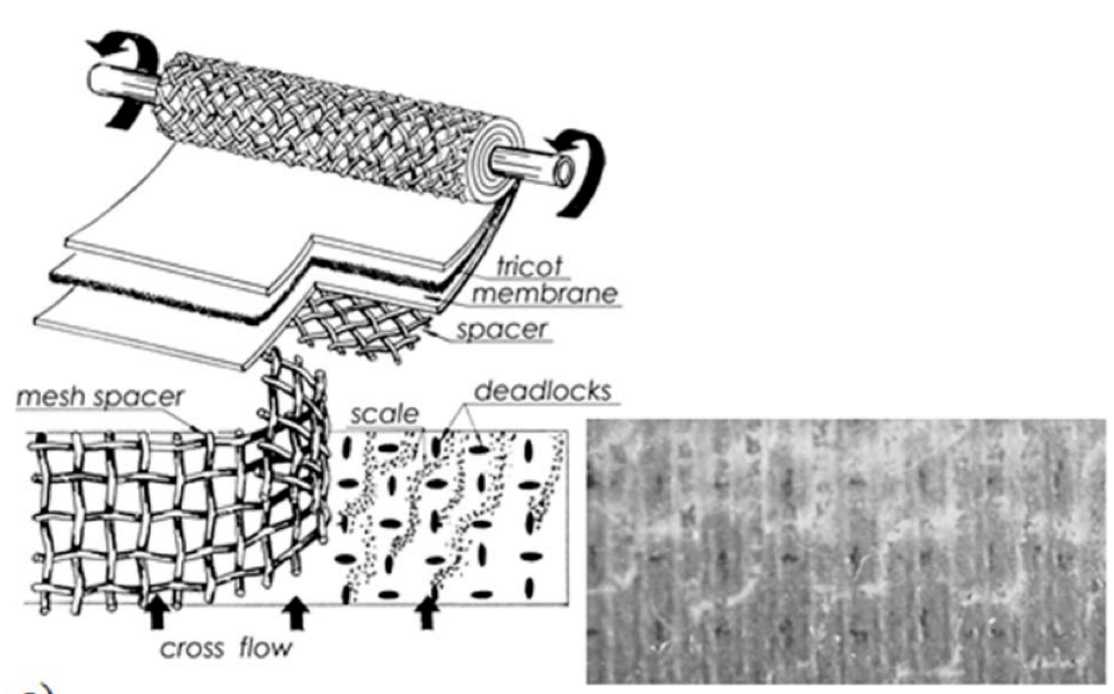

a)

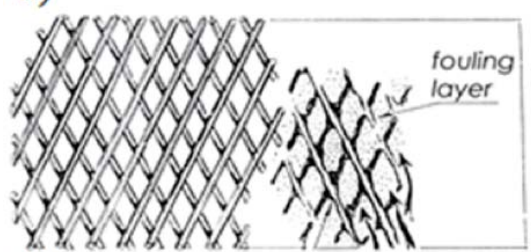

b)

Figure 3: Fouling and scaling: influence of space. Formation of crystals in dead areas: a) - formation of scale crystals; b) particle trapping and fouling layer formation.

devoted to the development of an open-channel spiral wound module. Modification of spiral wound module is shown on Figure 4 where the mesh is withdrawn from the channel by dividing it into ledges and so providing higher cross-flow velocities.

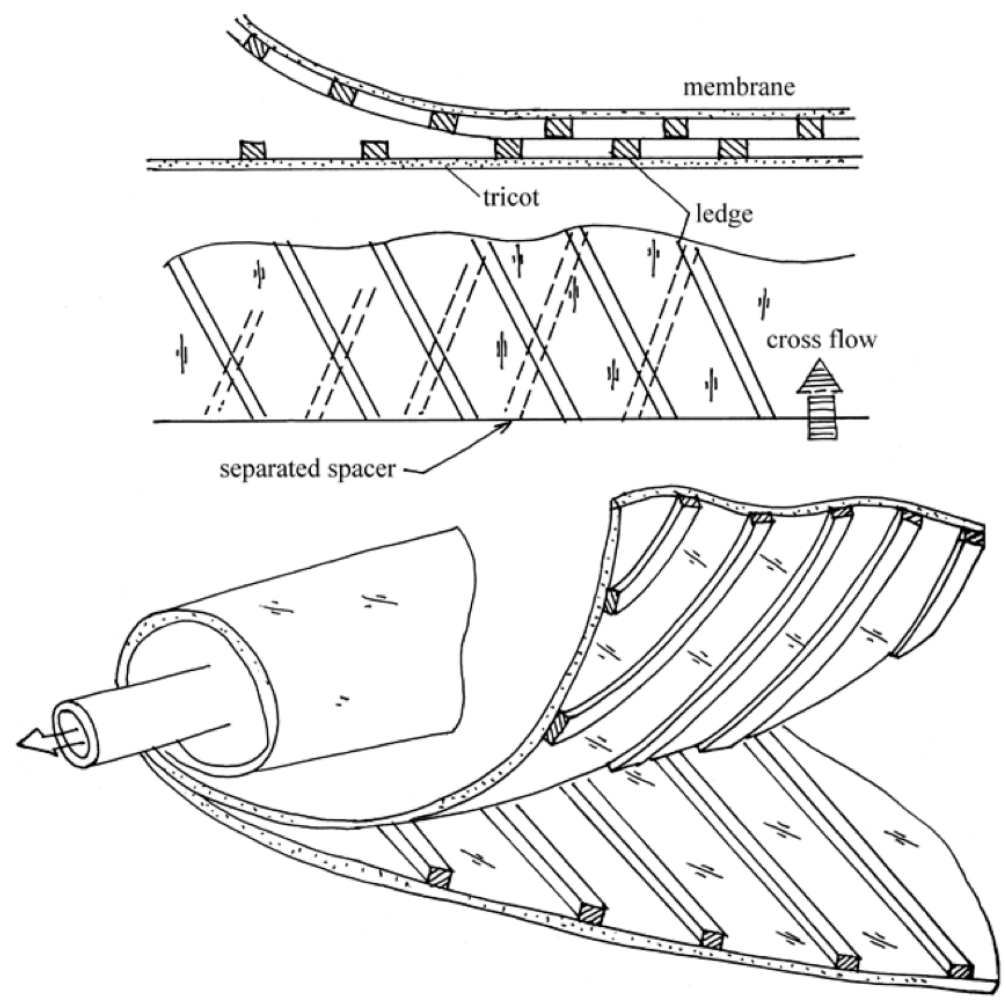

Figure 4: Spiral wound module with open-channel configuration. 
As was presented in a number of publications $[8,9]$, elimination of the spacer mesh from the feed channels of a spiral wound membrane configuration eliminates "dead regions" that provide scaling (crystal formation) and fouling conditions while also reducing the risk of particle "trapping" and the increase of associated dramatic flow resistance. Fouling control is achieved by providing sufficient cross-flow velocities, flushing, and cleanings.

RO membrane units can thus be used to efficiently treat wastewater and reuse it for technical and irrigation purposes. In a number of cases such as private housing and small enterprises it's reasonably possible to reduce tap water consumption and domestic water discharge in municipal sewer.

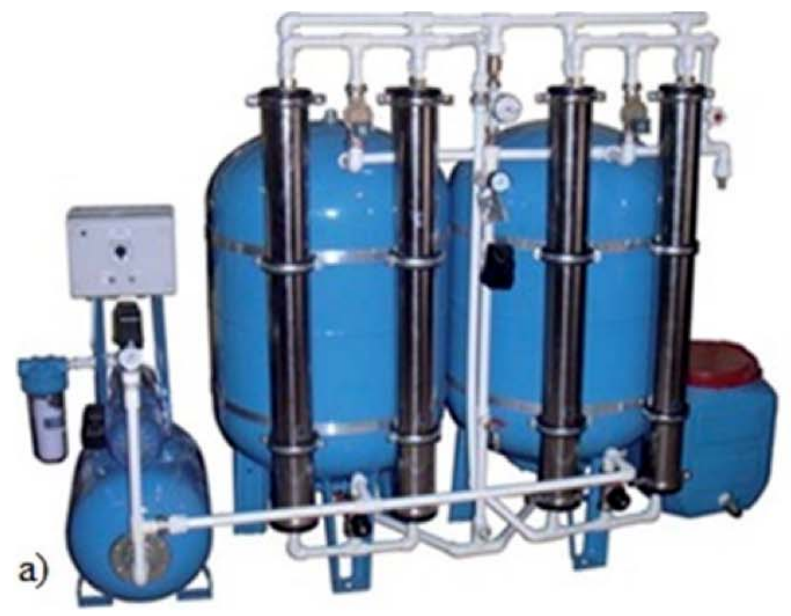

Introduction of a new "open channel" configuration offers a new perspective to escape fouling and to treat water with high fouling potential. Principles of development of a novel concept of wastewater treatment processes are developed, field-tested and introduced into practice.

Figure 5 shows a schematic flow diagram of an RO unit developed for wastewater treatment and reuse in a residential home. Wastewater is taken directly from the sewer; feed water passes through Miller Pump (that mills large size impurities such as paper, etc.), and is then forwarded to the screen that is automatically flushed to remove foulants and direct them back into a drain. Wastewater is then treated by RO membranes. The foulants that are accumulated on membrane b)

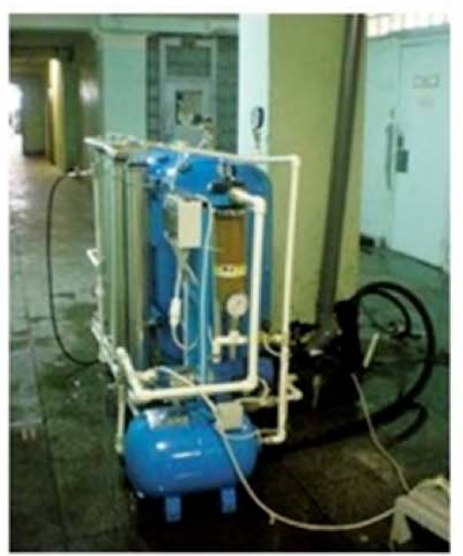

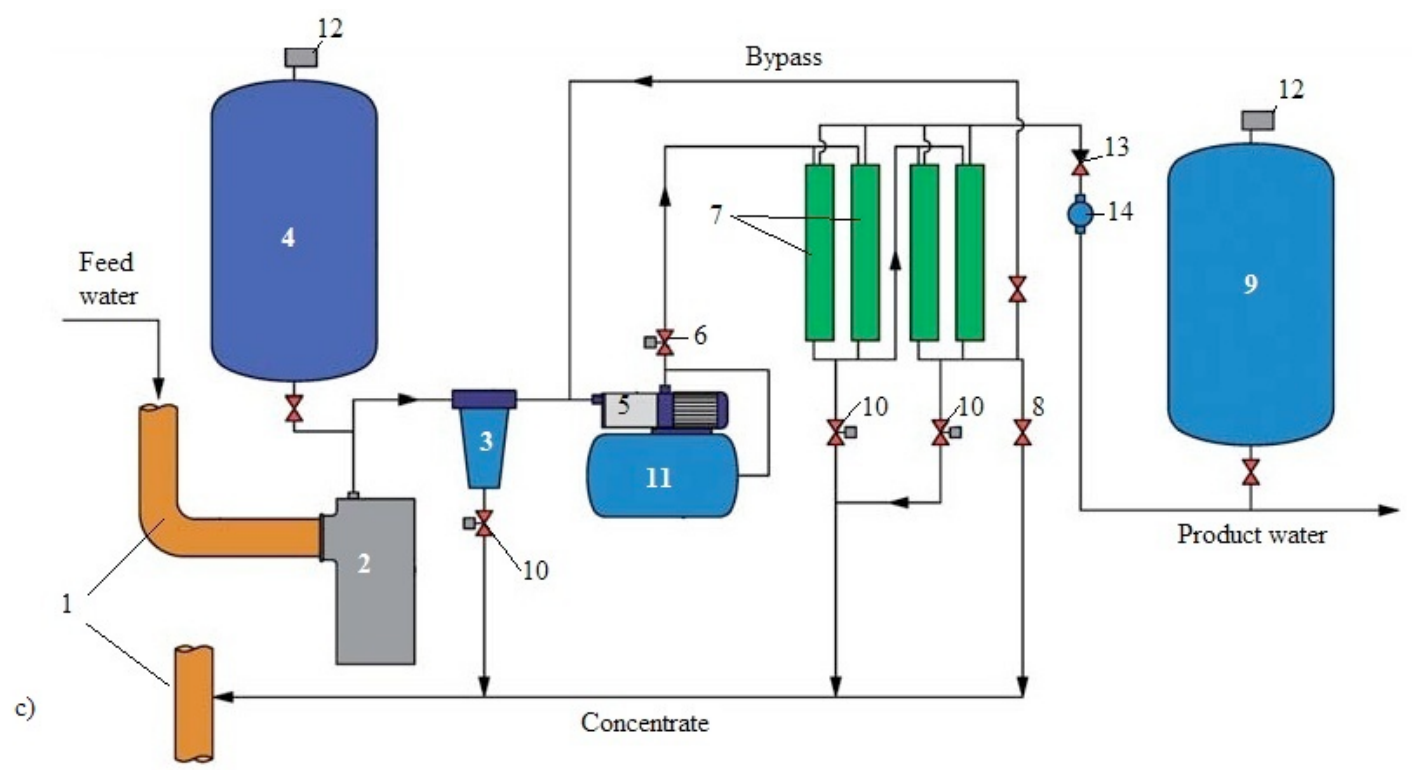

Figure 5: Reverse Osmosis unit to treat municipal wastewater.

a) pilot testing at the basement of the building; b) general view; c) flow diagram.

1- main sewer; 2- milling pump; 3 - backwashed screen mesh; 4 - feed water pressurized tank; 5- pressure pump; 6 - solenoid valve at the inlet; 7 -membrane modules; 8 - pressure gauge; 9 - product water pressurized tank; 10 - solenoid valves for flushing; 11 - pressurized flushing tank; 12 -pressure relay; 13 - check valve; 14 - flow counter. 
surface are periodically removed through application of membrane flushes. The membrane unit is operated in circulation mode that ensures high concentrate flow velocities that provide a "shear" effect to prevent sedimentation of suspended particles on membrane surface and membrane fouling. Product water can be used for technical purposes (plant watering, car washing, heating or cooling systems feed). The use RO unit provides reuse of $80-90 \%$ of domestic wastewater. Yet, the majority of utilities lack the legal permission to discharge RO concentrate. To evaluate developed measures to reduce concentrate flow and increase recoveries, a pilot testing program was implemented.

A new concept of direct wastewater treatment by $\mathrm{RO}$ is based on the following principles:

- using of membrane modules with an "open channel" enables us to avoid membrane fouling throughout their operation even with high suspended matter content in the feed water;

- membrane units are operated in the circulation mode with high cross flow velocities that provide the "shear effect" of adhered foulants;

- $\quad$ fouling control is achieved by providing sufficient cross flow velocities, flushes and cleanings; accumulated on membrane surface are withdrawn from membrane module during membrane flushes. Suspended matter after membrane flushes is collected, sedimented and finally dewatered.

- $\quad$ the main principles of high recovery maintenance are ensured by concentration of feed water in circulation mode by $50-100$ times by volume. Concentrate volume constitutes no more than $0,5-1 \%$ of the initial feed water volume and is withdrawn from the system together with a wet sludge as a sludge humidity.

In a number of cases (private housing, small community, local enterprise) it seems very efficient to decrease tap water consumption and domestic wastewater discharge into municipal sewer.

Contamination of water sources by oil products and detergents is considered as a serious environmental problem. Car washes and gas stations are mainly responsible for pollution with oil products.

Conventional treatment facilities (based on coagulation - sedimentation - filtration techniques) do not always remove contaminants to a level that meets modern discharge regulation standards. These techniques require high operational costs to reuse sorption filter beds as their sorption abilities are rapidly exhausted. Membrane applications (RO and NF) provide efficient removal of organic and inorganic compounds that ensure high water quality sufficient to reuse it for different industrial purposes. The developed membrane units tailored with "open channel" modules provide separation of wastewater into two streams: purified water and wet sludge that contains suspended matter and dissolved oil, detergents and other impurities.

The use of local membrane systems can radically change a concept of storm water treatment. All storm water collected after rainfall should not be treated for oil and detergent removal. Storm water can be collected and treated by RO in the "sources" of contamination , such as gas stations, parking lots, oil and gas storage tanks. For most storm water, conventional sedimentation and filtration facilities can be used that do not have high operational costs.

Storm water is treated by a double stage $\mathrm{RO}$ membrane unit, shown on Figure 6. A flow diagram of membrane units to treat storm water and car wash effluents is shown on Figure 7. Concentrate flow is decreased by 50 - 100 times and is withdrawn from the system together with wet sludge as a sludge moisture. At car washes, an equilibrium is reached between the amount of salt that enters the system with cleaning water and the amount of salt that is contained in the sludge that is removed from the system. To determine required membrane characteristics and optimum operational parameters, a test program was undertaken.

\section{EXPERIMENTAL PROCEDURE AND PILOT TEST PROGRAM}

A pilot unit was designed to ensure high increase of concentration values of all wastewater impurities and dissolved salts using a double stage concentration. The fieldtesting program was aimed at evaluation of membrane characteristics, recovery values and operational parameters for certain wastewater conditions.

At conventional biological treatment facilities the excessive activated sludge is withdrawn from the system. The volume of water in the sludge does not exceed $1 \%$ of the initial wastewater volume. Thus, 


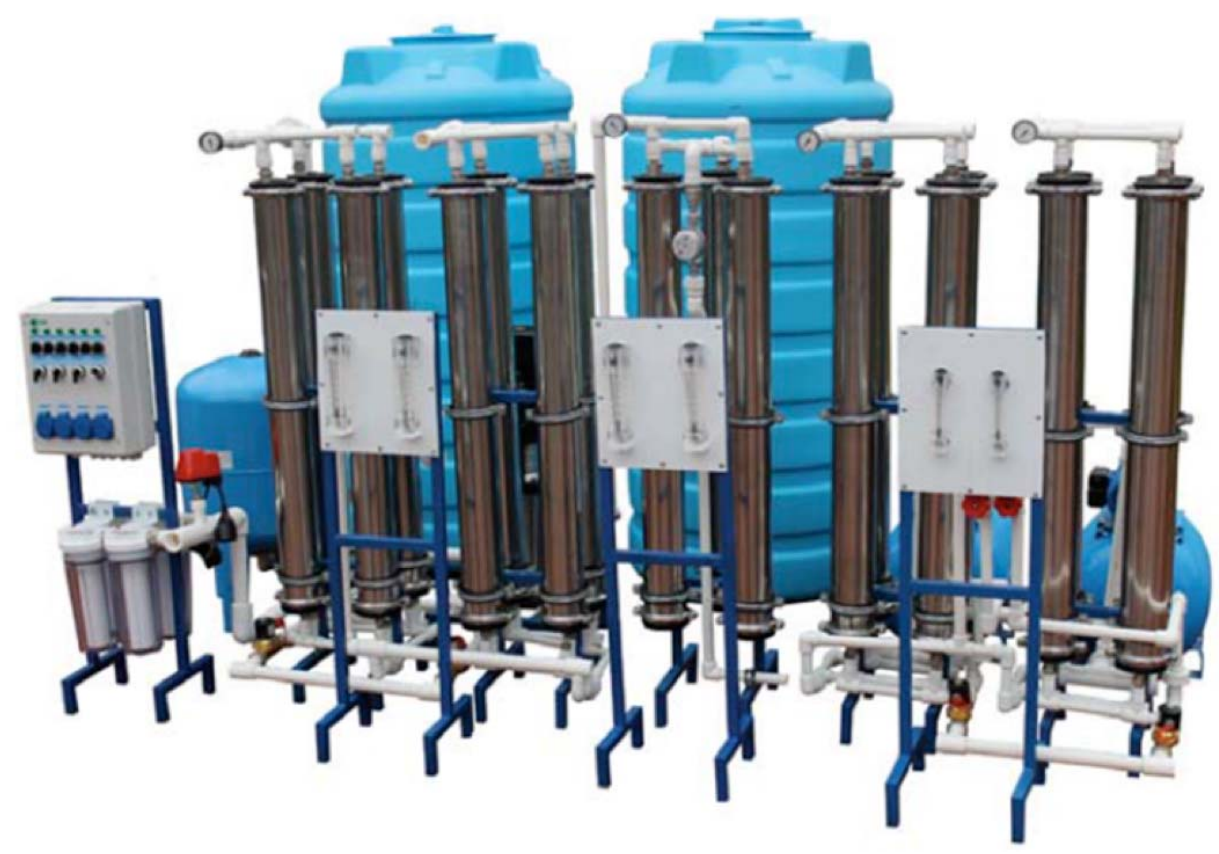

a)

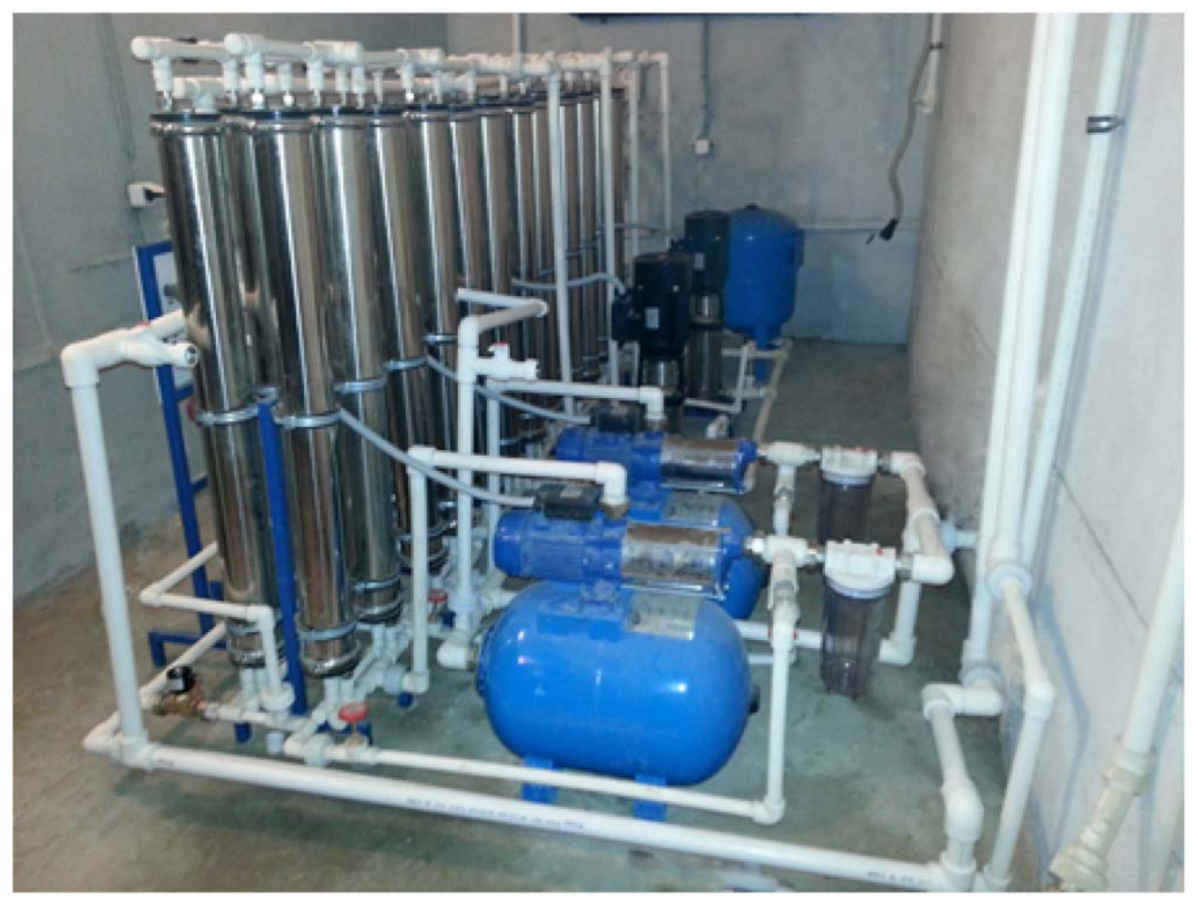

b)

Figure 6: Double stage RO membrane unit for wastewater treatment, 6 cubic meter per hour capacity: a) photo of the unit, general view; b) operation of the membrane unit at local storm water treatment facilities.

membrane plant should not only purify wastewater and remove ammonia, phosphate, BOD, etc., but also to reduce concentrate flow by 100 times (as compared to initial feed water flow). The second stage is used to reduce energy costs while concentrating dissolved salts and organics that increase osmotic pressure. Concentrate of the first stage (constituting about $20 \%$ of the initial flow) enters the second stage "tailored" with nanofiltration membranes. Product flow of the second stage is mixed with feed water. The pilot unit contains sedimentation tanks, concentration tanks and membrane flushing systems.

Figure 8a shows the developed pilot plant producing 300 liters per hour for purification of domestic wastewater and concentrate utilization. The pilot plant was installed and successfully operated at wastewater treatment facilities that treat domestic wastewater of a 


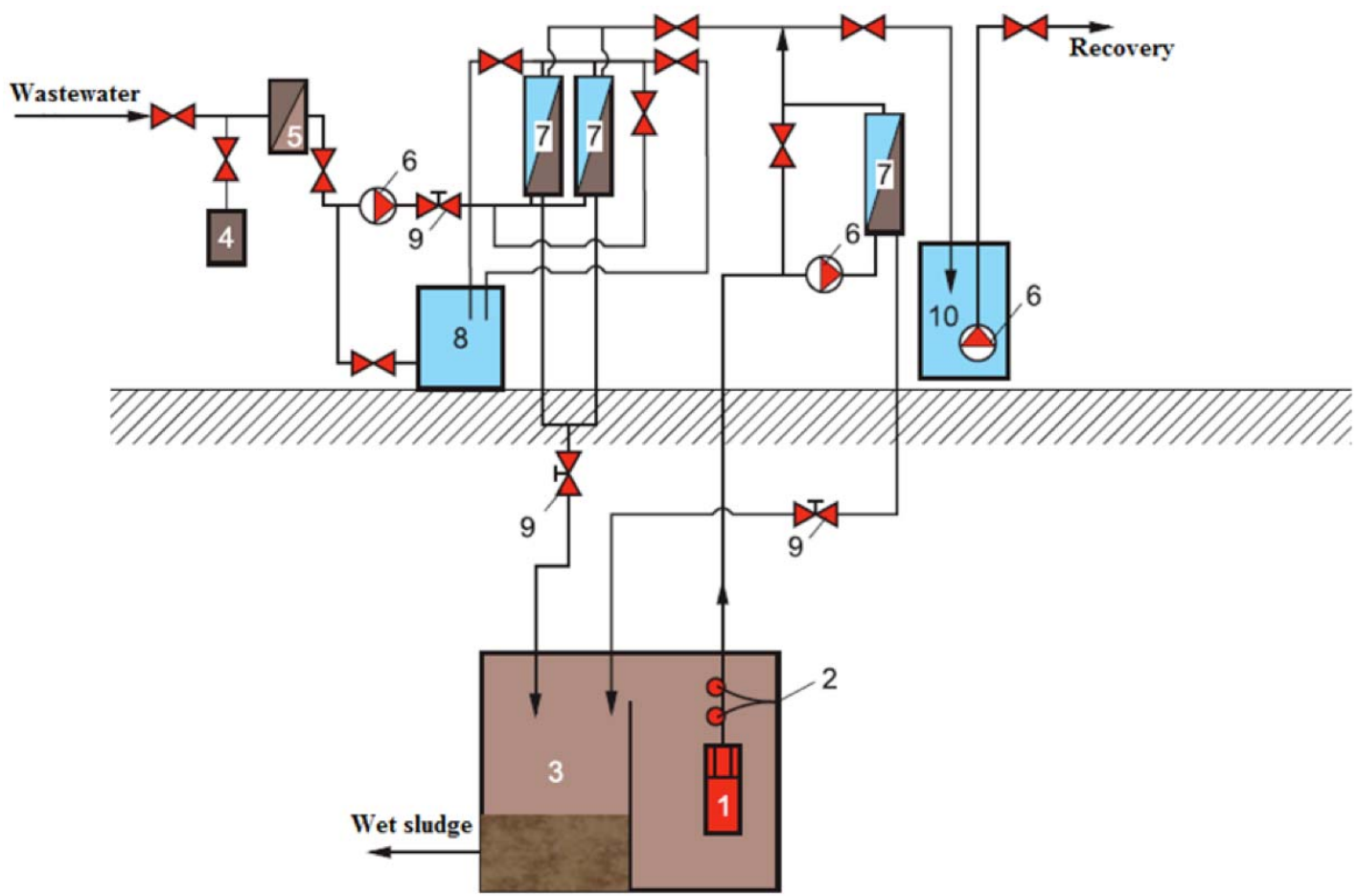

Figure 7: Schematic flow diagram of storm water treatment.

1 -wastewater well pump; 2 - float switch; 3 -sedimentation tank; 4 -accumulation tank; 5 - pretreatment screen; 6 -pressure pump; 7 - membrane modules; 8- cleaning tank; solenoid valve; 9 - product water tank.

Gas Pumping station - an Enterprise that belongs to Gasprom (Russia). The ecological situation at the enterprise location at the agricultural district does not permit to discharge even biologically treated and post treated water basing on strict requirements of phosphate, ammonia, sodium and chloride concentrations (Table 2). In certain cases where ammonia removal requirements are very strict, double stage RO can be applied (Table 2).

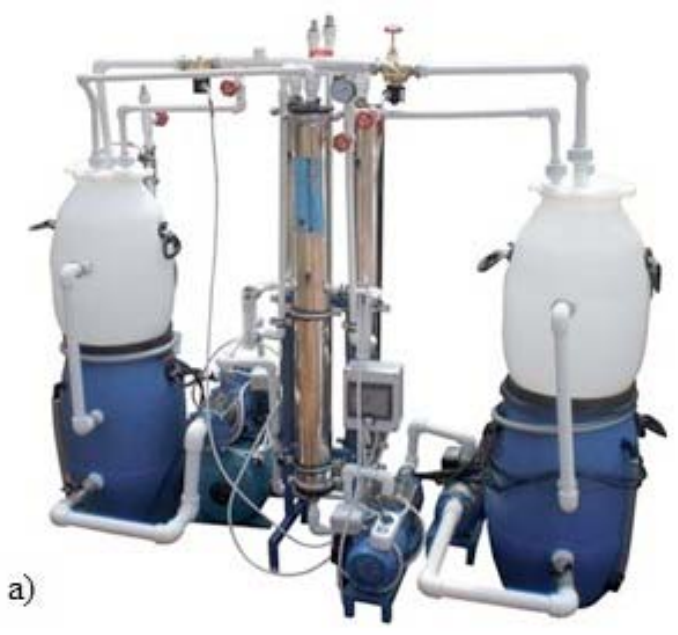

The location of the pilot unit at the wastewater treatment facilities is shown in Figure $\mathbf{8 b}$. Schematic flow diagram of the pilot unit is shown in Figure 9. The unit is developed to demonstrate possibilities of reducing concentrate flow to $1 \%$ of the initial feed water volume, and all wastewater impurities could be discharged together with wet sludge as sludge turbidity.

The field testing program was aimed at evaluation of membrane characteristics, recovery values, and b)

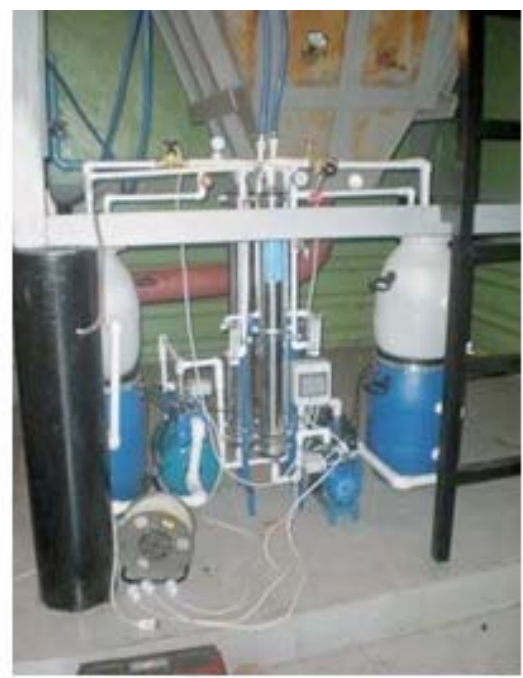

Figure 8: Membrane pilot plant for wastewater treatment and concentrate utilization: a) 300 liter per hour membrane pilot plant; b) pilot testing at municipal wastewater facilities. 
Table 2: Waste Water Composition During Different Purification Stages

\begin{tabular}{|c|c|c|c|c|c|c|}
\hline Index & $\begin{array}{c}\text { Feed } \\
\text { waste- } \\
\text { water }\end{array}$ & $\begin{array}{l}\text { First RO stage } \\
\text { product }\end{array}$ & $\begin{array}{l}\text { Second stage } \\
\text { product }\end{array}$ & $\begin{array}{c}\text { Water after } \\
\text { biological treatment }\end{array}$ & RO product & $\begin{array}{c}\text { Regulation } \\
\text { permitted } \\
\text { discharge }\end{array}$ \\
\hline $\begin{array}{c}\text { Suspended solids } \\
\mathrm{mg} / \mathrm{L}\end{array}$ & 124 & 0.2 & 0 & 75 & 0.5 & 7.6 \\
\hline $\mathrm{pH}$ & 7.9 & 7.1 & 6.3 & 8.1 & 7.3 & $6.5-7.5$ \\
\hline $\mathrm{NH}_{4}{ }^{+}, \mathrm{mg} / \mathrm{L}$ & 12.8 & 0.43 & $<0.05$ & 4.1 & 0.21 & 0.189 \\
\hline $\mathrm{NO}_{3}, \mathrm{mg} / \mathrm{L}$ & - & - & - & 26.5 & 0.62 & 7.44 \\
\hline $\mathrm{NO}_{2}, \mathrm{mg} / \mathrm{L}$ & - & - & - & 0.59 & 0.17 & 0.0075 \\
\hline $\mathrm{PO}_{4}, \mathrm{mg} / \mathrm{L}$ & 2.44 & 0.1 & 0 & 0.62 & 0.07 & 0.401 \\
\hline $\mathrm{COD}, \mathrm{mg} / \mathrm{L}$ & 190 & 32 & 8.8 & 104 & 24 & - \\
\hline $\mathrm{SO}_{4}, \mathrm{mg} / \mathrm{L}$ & 71 & 3.8 & 0.25 & 69 & 3.7 & - \\
\hline $\mathrm{Cl}, \mathrm{mg} / \mathrm{L}$ & 142 & 14.1 & 1.6 & 149 & 15 & - \\
\hline TDS mg/L & 738 & 72 & 8.3 & 729 & 71 & - \\
\hline
\end{tabular}

operational parameters for certain wastewater conditions. At conventional biological treatment facilities the excessive activated sludge is withdrawn from the system. The volume of water in the sludge does not exceed $1 \%$ of the initial wastewater volume.

Thus, membrane plant should not only purify wastewater and remove ammonia, phosphate, BOD, etc., but also to reduce concentrate flow by 100 times (as compared to initial feed water flow). The second stage is used to reduce energy costs while concentrating dissolved salts and organics that increase osmotic pressure.

Concentrate of the first stage (constituting about $20 \%$ of the initial flow) enters the second stage "tailored" with nanofiltration membranes. Product flow of the second stage is mixed with feed water. The pilot unit contains sedimentation tanks, concentration tanks, and membrane flush systems.

The double stage RO pilot unit was developed to study possibilities of purifying wastewater for its further reuse. The design and equipment used in the unit (flow diagram, membrane modules and pumps) enable us to develop required operational modes (such as membrane rejection and product quality, recovery, pressure values) depending on the feed wastewater quality. Reverse osmosis membranes reject dissolved ionic species (ammonia, nitrates, phosphates) and organics (derived as BOD). RO membranes used at the first stage of $\mathrm{RO}$ pilot unit remove all required impurities from wastewater to meet standards for effluents discharged into surface water sources. The use of a second stage tailored with nanofiltration (or low pressure $\mathrm{RO}$ membranes) reduces concentrate flow by 100 times or greater without additional power costs. Product water after second stage membranes is mixed with the feed water.

When biological treatment is used, the excessive amount of activated sludge is sedimented in the secondary sedimentation tanks and then forwarded to the sludge bed. The water flow withdrawn with activated sludge (that constitutes its humidity) does not exceed 1 per cent of the initial wastewater flow.

Therefore, the challenge of application of $\mathrm{RO}$ techniques to purify domestic wastewater is not only to produce quality product water, but to reach recovery values up to $99 \%$ and even higher. The concentrate flow after the first stage (that constitutes from 10 to $20 \%$ of initial flow value) is then treated at the second stage where nanofiltration membranes are used with $70 \%$ rejection value. Nanofiltration membranes are used to reduce operational costs when $\mathrm{RO}$ concentrate with high TDS and organic content (increased osmotic pressure value) is treated.

Initial wastewater flow after the second stage is reduced by 100 times and has TDS value 25,000 30,000 ppm. To maintain the second stage membrane unit permeability on the 6-8 liter/ hour sq. meter level, working pressure of 14-15 Bar is applied.

The flow diagram of the test unit is presented in Figure 9. The initial water flow (biologically treated or domestic wastewater) enters the inlet feed water sedimentation tank (4) and is poured into the feed water concentration tank (5). After the tank (5) is filled, 


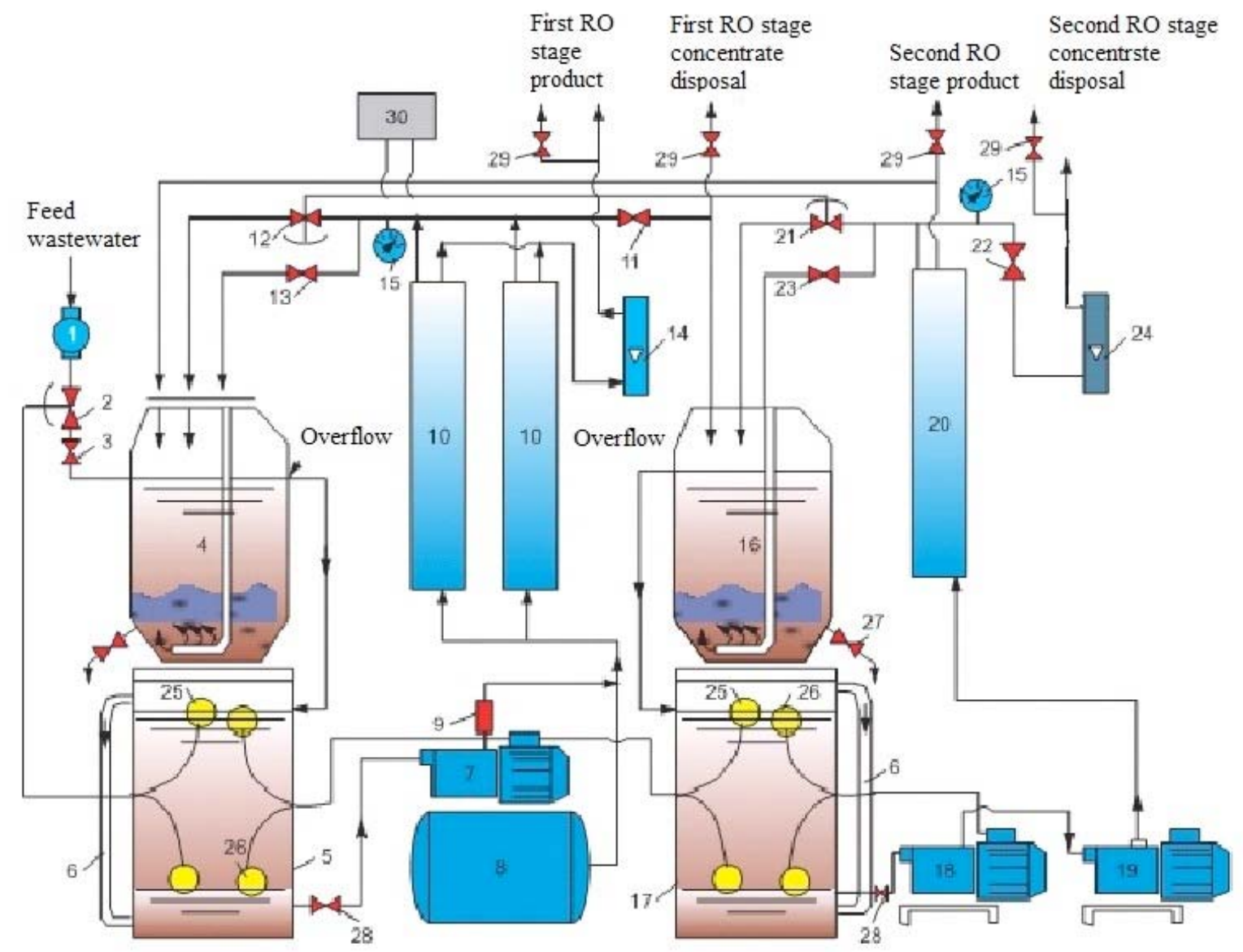

Figure 9: Flow diagram of membrane pilot plant to treat municipal wastewater with $99 \%$ concentrate recovery.

1 - feed water flow meters; 2 - solenoid valve at the inlet; 3 - pressure gauge; 4 - feed water tank; 5 - feed water concentrate tank; 6 - level censor; 7 - first RO stage pump; 8 - pressure tank for flushing; 9 - check valve; 10 - first stage RO module; 11 - first stage RO concentrate pressure gauge ; 12 - first stage flushing solenoid valve; 13 - first stage RO bypass valve; 14 - first stage product water flow meter; 15 - manometer; 16 - first stage concentrate collection tank; 17 - second stage RO concentrate tank; 18 - second stage feed pump; 19 - second stage RO pressure pump; 20 - second stage RO membrane module; 21 - second stage membrane flushing solenoid valve; 22 - second stage concentrate pressure gauge; 23 - second stage bypass valve; 24 second stage concentrate flow meter; 25 - tank level control; 26 - low level control; 27 - sediment withdrawal valve; 28 - valves; 29 - sampling valves; 30 - solenoid valve controller.

a float tank level control switch closes the solenoid valve (2) at the initial water inlet. The initial water flow is regulated by a pressure gauge (2) at the inlet and controlled by a water flow meter (1).

Wastewater from the tank (5) is pumped by a centrifugal pump Speroni RSM-5 (pressure 6-8 Bar) to the first stage membrane modules. Two membrane spiral wound modules are used on the first stage of 4040 standard, (TFC BLN membrane, supplied by CSM, Korea). The first stage product water can be used (reused) for technical purposes or discharged. Pressure value in the first stage membrane modules is maintained on 6-8 Bar level and controlled by pressure gauge (11) and manometer (15).

To maintain a cross-flow mode, concentrate flow after first RO stage is returned back to tank (4) using by-pass valve (13). A part of the first stage concentrate (10-20\%) enters first stage concentrate collection tank (16), which is also used at the second stage inlet. To remove colloidal and suspended particles that are sedimented on the membrane surface, hydraulic flushes are applied. The flushing procedure consists of opening the solenoid valve (12) and discharging the first stage concentrate. When the solenoid valve (12) opens, the pressure drops and the increased flow "flushes" foulants off the membrane surface and discharges them into the sedimentation tank (4). To increase the flush flow value, a pressure tank (8) is used.

The second stage unit is used to further decrease the RO concentrate volume. Concentrate from the second stage RO concentrate tank (17) is pumped into the membrane nanofiltration module (20). The module 
of 4040 standard uses $70 \mathrm{NE}$ membranes (CSM, Korea). To provide pressure value of 14-15 Bars, two Speroni RSM-5 pumps were used (one-by-one).The second stage pressure value is controlled by a pressure gauge (22) and manometer (15). When the test unit is started-up, a certain time is required to reach stable operation characteristics (concentrate flow and TDS). While concentrate volume is reduced during membrane unit operation, membrane product flow (in the first and second stages) also decreases. Figure $\mathbf{5}$ shows the increase of the first and second stage concentrate TDS and membrane product flow decrease with time during the start-up period.

Product water after the second stage is returned to the feed water tank (4), Figure 9. The smallest part of concentrate ( $1 \%$ of initial water flow) is discharged from the unit together with sedimented sludge for further dewatering. Other concentrate is returned to the tank (16) through bypass valve (23).

The sedimented sludge, which is removed from membrane surface during flushing, is withdrawn from tanks (4) and (16) using valves (27).
First stage product water and second stage concentrate flows are controlled by flow meters (14) and (24). To control concentrate and product water quality, sampling valves (29) are used.

Accumulated foulant is withdrawn from the second stage membrane surface by applying flushes that consist of opening the solenoid valve (21). Automatic mode uses float switches (25) and (26). First stage pump (7) stops when tank (17) is full and when tank (5) is empty using tank level control switch (25). The second stage pumps (18) and (19) are stopped using tank level control switch (26) when tank (17) is empty. Signal from monitor (30) opens the Solenoid valves (12) and (21) using time relays. The duration of each flush and the flush schedules are programmed depending on wastewater composition and operational mode.

In our pilot experiments, flushes were organized after two-three hours of constant operation, flush duration was $10-20$ seconds.

To reach maximum ecological efficiency, the developed RO process should account for local

a)

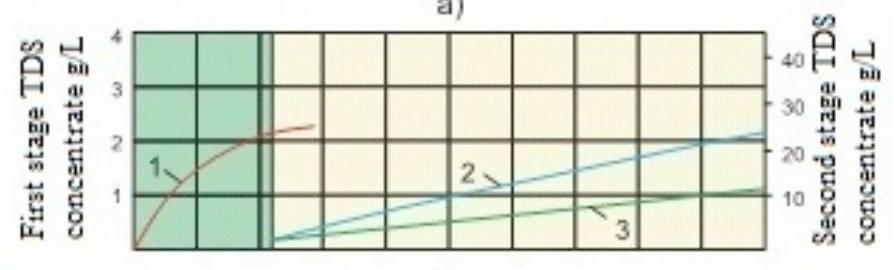

b)

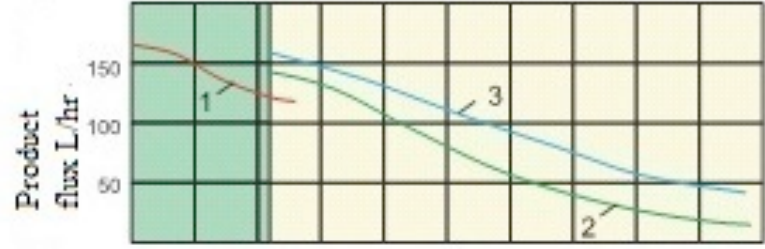

c)

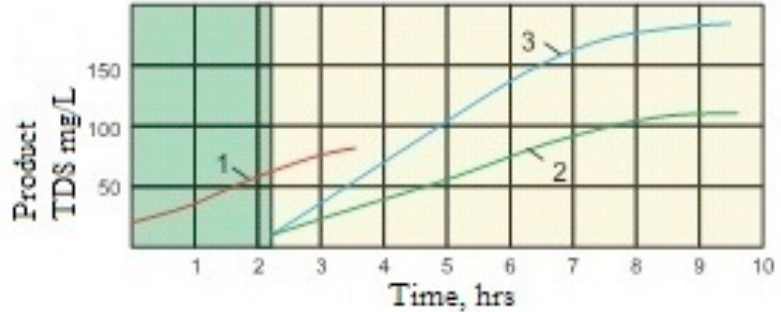

First stage

Second stage

Figure 10: Variations of membrane performance with time and during recovery increase and concentrate utilization: a) Concentrate TDS growth; b) Product flow decrease; c) Product TDS growth.

1 - BLN membrane (CSM); 2 - 90 NE membrane (CSM); 3 - 70 NE membrane (CSM). 
Table 3: The Influence of Wastewater Salinity on RO Recovery

\begin{tabular}{|c|c|c|c|c|c|}
\hline \multirow[t]{2}{*}{ Index } & \multicolumn{5}{|c|}{ Wastewater salt content, $\mathrm{mg} / \mathrm{L}$} \\
\hline & 800 & 400 & 200 & 100 & 50 \\
\hline $\begin{array}{c}\text { Feed water } \\
\text { consumption, } \mathrm{m}^{3} / \text { day }\end{array}$ & 100 & 100 & 100 & 100 & 100 \\
\hline Product TDS, mg/L & 40 & 20 & 10 & $5-6$ & $3-5$ \\
\hline $\begin{array}{l}\text { Wastewater concentrate } \\
\text { flow (discharged as } \\
\text { sludge humidity), } \mathrm{m}^{3} / \text { day }\end{array}$ & $3.8^{*}$ & $1.9^{*}$ & 0.9 & 0.48 & 0.24 \\
\hline $\begin{array}{c}\text { Wastewater concentrate } \\
\text { TDS mg/L }\end{array}$ & 20000 & 20000 & 20000 & 20000 & 20000 \\
\hline
\end{tabular}

${ }^{\star}$ Further recovery increase can be achieved by using additional nanofiltration membranes.

conditions when applied for wastewater reuse. The efficient solution of wastewater reuse for local utilities suggests an application of membrane units for boiler feed and drinking water production. This statement has a following explanation. Table $\mathbf{3}$ and Figure $\mathbf{1 0}$ data show that concentrate flow for the certain conditions depends on wastewater TDS. When low pressure RO and NF membranes are applied, it is reasonable to operate the test unit when concentrate TDS does not exceed 25000 - 30000 ppm. Membrane flux becomes very low under these conditions. To reach higher recoveries, higher pressure is required that needs different membrane and pumping equipment as well as higher power consumption. The lower the initial TDS value, the higher the recovery value that can be reached (Table 3).

Therefore, to decrease concentrate flow (i.e. to increase recovery), feed water TDS should be reduced. To reduce municipal wastewater TDS, RO membrane units can be used to produce drinking water. Municipal wastewater TDS is also very dependent on the amount of ion exchange water softeners (and their effluents) used for boiler feed and drinking water production for the certain utilities. Application of local RO membrane units for boiler feed and drinking water production could significantly decrease wastewater TDS. For the use of developed "open channel" membrane modules, the principles of RO concentrate utilization are described in previous publications [9].

Membrane treatment efficiencies to remove oil products, detergents, to reduce BOD and TDS under described RO operation conditions (with concentrate volume decreased by $99 \%$ ) were investigated. Tables 4 and 5 show membrane treatment efficiencies in separating storm water and car wash effluent depending on product recovery values. A test program was undertaken to investigate rejection of membranes versus recovery values. A flow diagram of the test unit is shown on Figure 11.

Results of tests are illustrated in Figures 12, 13, 14, 15 and 16. Figure 12 shows the drop of membrane flux with recovery increase throughout test run.

When recovery reaches $0,9-0,95$ value, product flow decreases by 2,5 -3 times. Further recovery increase

Table 4: Concentration Values of Different Water Impurities in Feed Water, Product and Concentrate Throughout Storm Water Treatment

\begin{tabular}{|c|c|c|c|c|c|c|c|c|c|}
\hline & Normal & $\begin{array}{l}\text { Feed } \\
\text { waste- } \\
\text { water }\end{array}$ & $\begin{array}{c}\text { Average } \\
\text { RO } \\
\text { product }\end{array}$ & $\begin{array}{c}\text { Second } \\
\text { RO stage } \\
\text { product }\end{array}$ & $\begin{array}{c}\text { Second } \\
\text { RO } \\
\text { concentrate }\end{array}$ & $P \times 10$ & $C \times 10$ & $P \times 90$ & C $\times 90$ \\
\hline $\begin{array}{l}\text { Suspended } \\
\text { solids } \mathrm{mg} / \mathrm{L}\end{array}$ & 3 & 23,8 & 0,39 & 0,29 & 34,0 & 1,56 & 29,7 & 3,4 & 119 \\
\hline $\mathrm{BOD}, \mathrm{mg} / \mathrm{L}$ & 3 & 7,24 & 4,7 & 4,0 & 177,0 & 21,6 & 463 & 43,8 & 784 \\
\hline $\mathrm{Cl}, \mathrm{mg} / \mathrm{L}$ & - & 266,0 & - & - & 568,0 & 114,0 & 1392 & 795 & 5822 \\
\hline $\mathrm{Fe}, \mathrm{mg} / \mathrm{L}$ & 0,1 & 1,72 & 0,106 & 0,169 & 2,3 & 0,44 & 1,64 & 0,044 & 6,2 \\
\hline Oil, mg/L & 0,05 & 0,55 & $<0,01$ & 0,06 & 1,27 & 0,09 & 1,21 & 0,188 & 10,1 \\
\hline $\mathrm{TOC}, \mathrm{mg} / \mathrm{L}$ & - & 0,494 & 0,046 & 0,232 & 0,292 & 0,051 & 0,944 & 0,054 & 1,86 \\
\hline TDS, mg/L & 1000 & 465 & 363 & 50 & 1280 & 250 & 3580 & 2700 & 12150 \\
\hline
\end{tabular}


Table 5: Concentrations of Oil, Detergents, BOD in Product Water and Concentrate of RO System During Car Wash Effluent Treatment

\begin{tabular}{|c|c|c|c|c|c|c|c|c|}
\hline & $\begin{array}{l}\text { Feed } \\
\text { waste- } \\
\text { water }\end{array}$ & $\begin{array}{l}\text { Average RO } \\
\text { product }\end{array}$ & $\begin{array}{l}\text { First RO } \\
\text { stage } \\
\text { product T }\end{array}$ & $\begin{array}{c}\text { First } \\
\text { RO concentrate }\end{array}$ & $P \times 2$ & $C \times 2$ & $P \times 20$ & $C \times 20$ \\
\hline $\begin{array}{l}\text { Suspended } \\
\text { solids } \mathrm{mg} / \mathrm{L}\end{array}$ & 49,6 & $<0,10$ & $<0,10$ & 80,2 & 0,389 & 104,0 & $<0,10$ & 186,0 \\
\hline $\mathrm{BOD}, \mathrm{mg} / \mathrm{L}$ & 65,7 & 2,84 & 3,81 & 164,0 & 14,6 & 93,1 & 16,0 & 275,0 \\
\hline Oil, mg/L & 4,19 & 0,081 & $<0,001$ & 6,0 & 0,114 & 8,8 & 0,372 & 13,4 \\
\hline $\mathrm{TOC}, \mathrm{mg} / \mathrm{L}$ & 0,262 & 0,001 & 0,008 & 0,048 & 0,004 & 0,044 & 0,013 & 0,753 \\
\hline TDS, mg/L & 774 & 53,2 & 21 & 972 & 32,8 & 1770 & 306 & 8910 \\
\hline
\end{tabular}

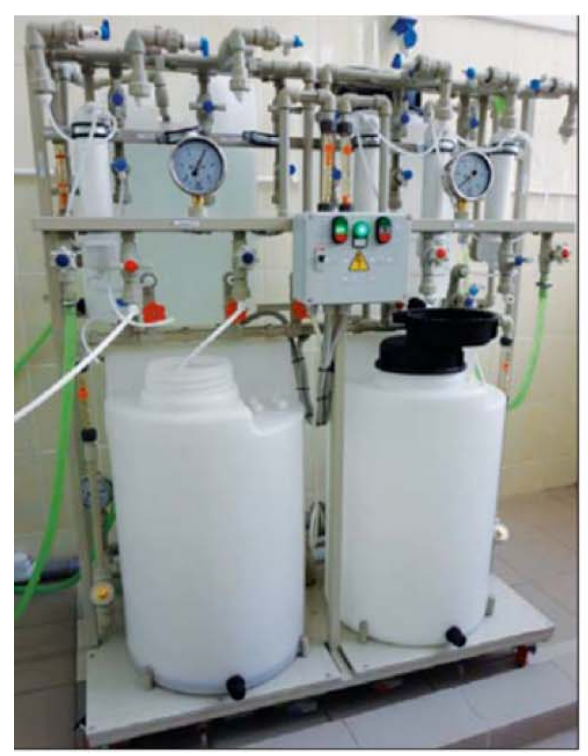

a

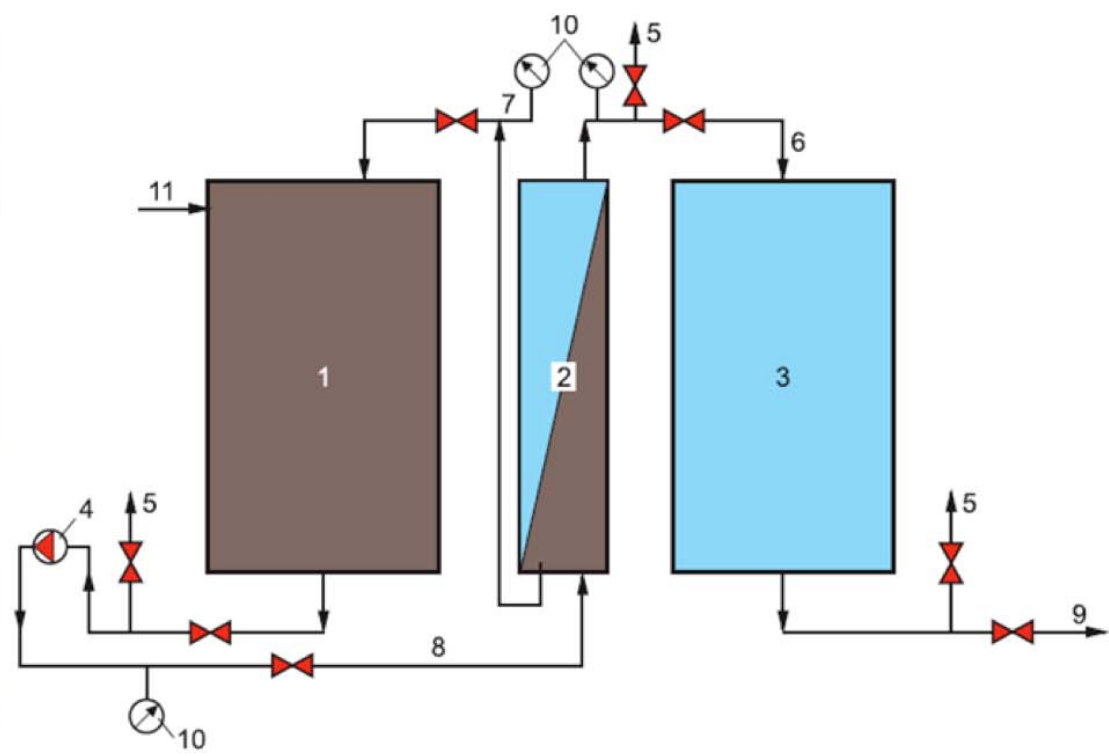

b

Figure 11: Double stage RO membrane unit for laboratory tests: $\mathbf{a}$ - photo; $\mathbf{b}$ - flow diagram.

1 - feed water tank; 2 - membrane module; 3 - product water tank; 4 - pressure pump; 5 - tap of sampling; 6 - product water; 7 RO concentrate; 8 - feed water; 9 - product water; 10 - manometer.

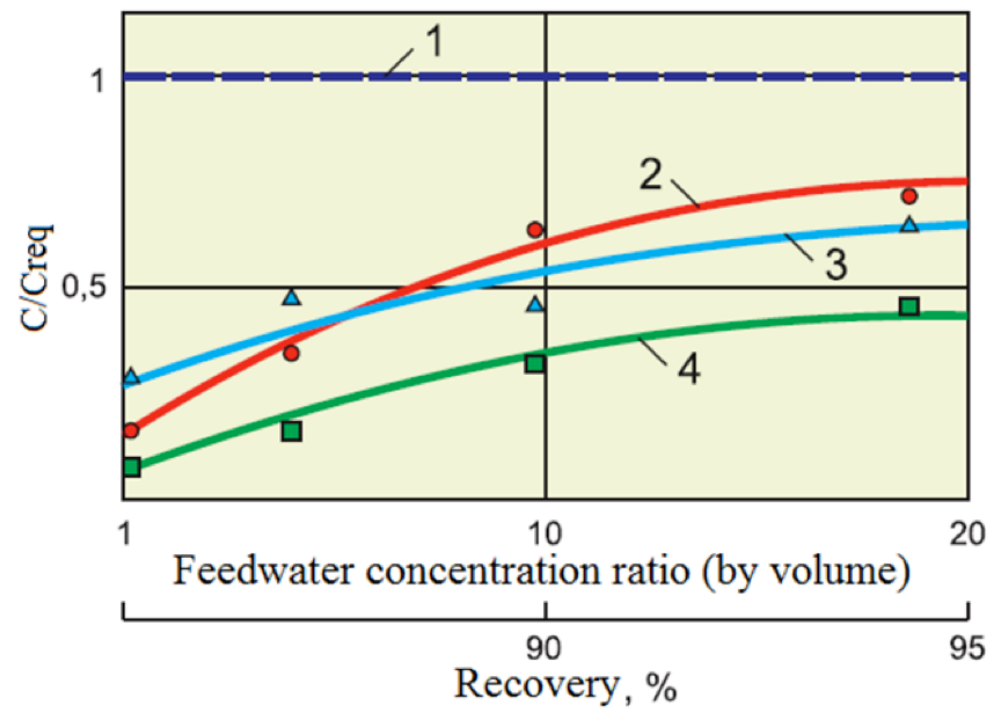

Figure 12: Dependence of $\mathrm{C} / \mathrm{C}_{\text {req. }}$ value on concentration factor and recovery values.

1 - $\mathrm{C}_{\text {req. }}$ (required value of contaminant concentration); 2 - BOD; 3 - detergents; 4 - oil products. 


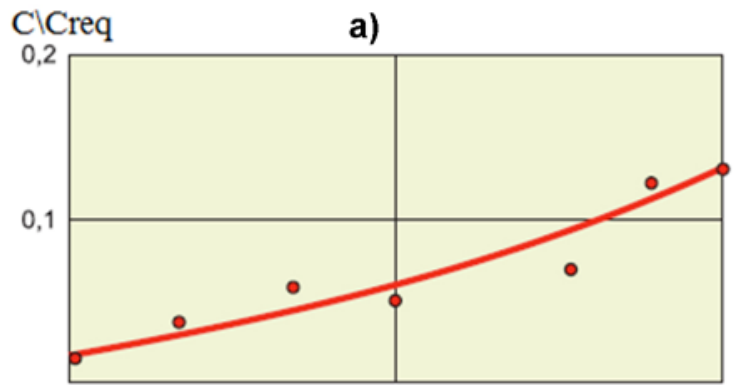

c)

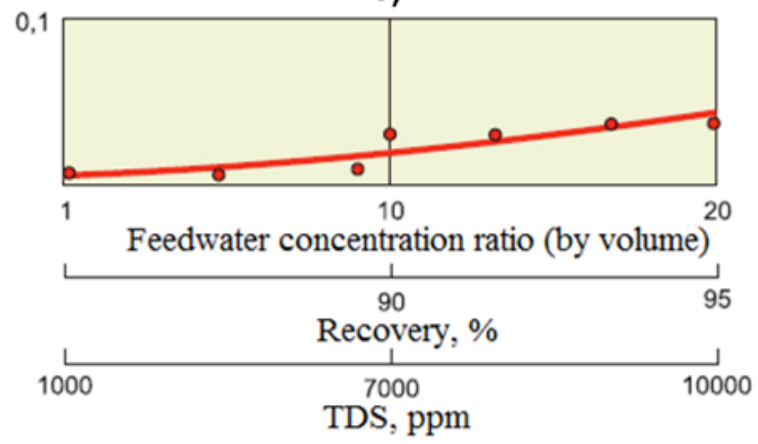

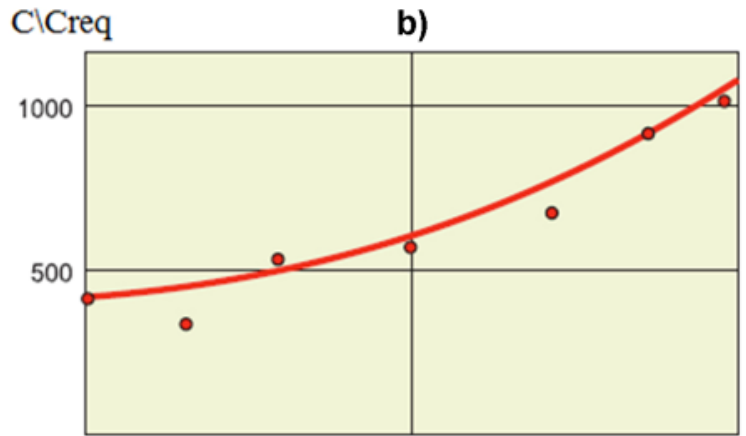

d)

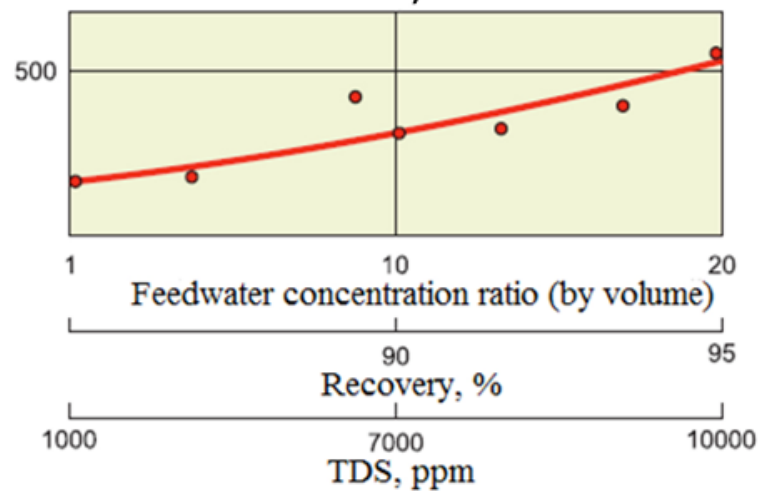

Figure 13: Increase of oil, detergents, BOD and TDS in product water versus recovery and concentration factor throughout test run.

a - detergents; $\mathbf{b}$ - TDS; $\mathbf{c}$-oil products; $\mathbf{d}$ - BOD.

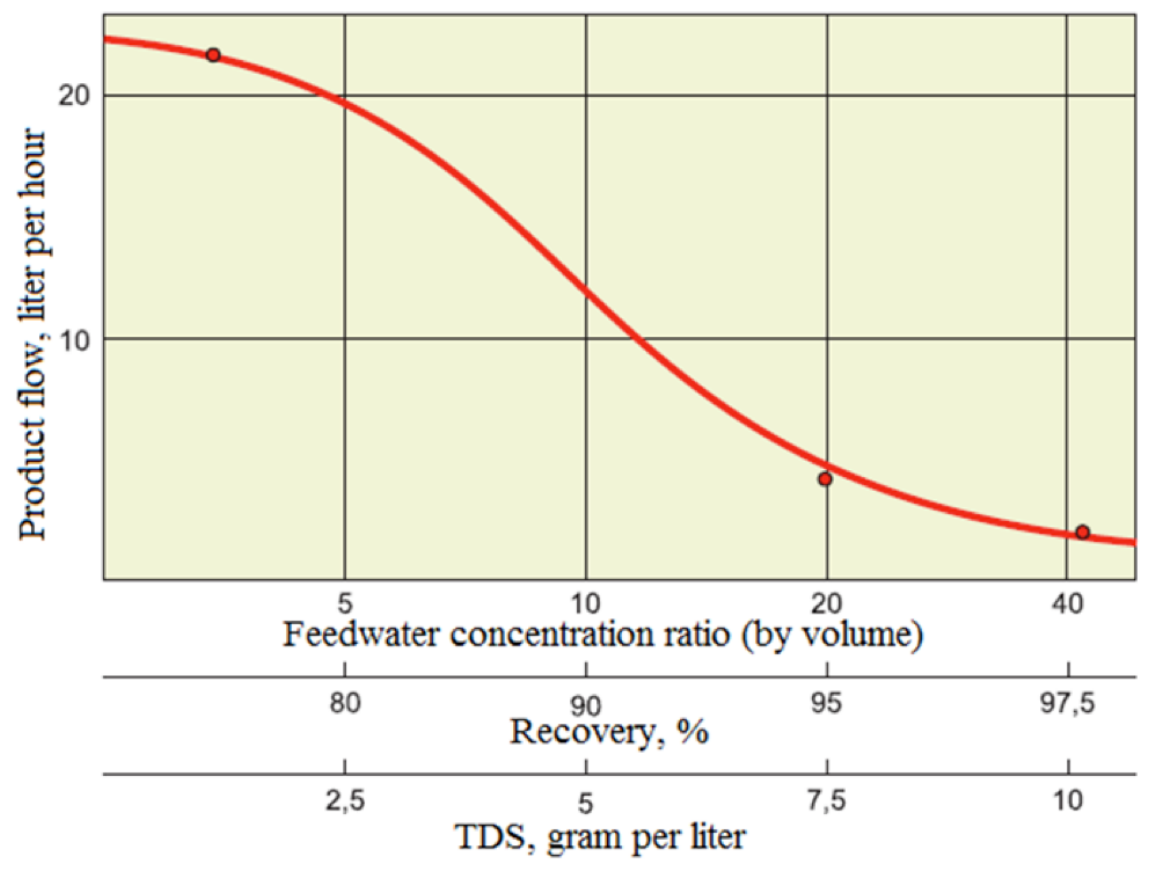

Figure 14: Reduction of product flow with TDS growth during storm water treatment by double stage RO..

requires application of second stage membranes operated under higher pressure value. Figure 13 demonstrates relationships of BOD, detergents and oil concentration values in product water on recovery. Reverse osmosis efficiencies can be represented by
$\mathrm{C} / \mathrm{C}_{\text {req }}$ ratio value as a function of recovery, where $\mathrm{C}$ is concentration value of the certain impurity in product water and $\mathrm{C}_{\text {req }}$ is its required concentration value in product water discharged into surface water source according to existing regulations. Figure 14 shows 


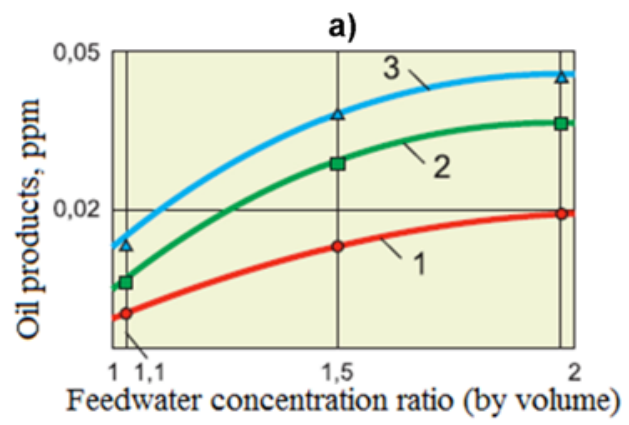

b)

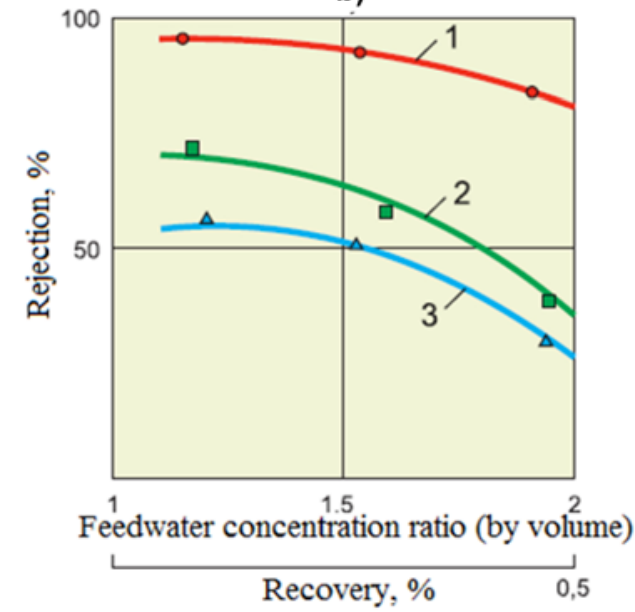

Figure 15: Dependencies of oil concentrations in product water (a) and oil rejection (b) on concentration factor and recovery.

1 - feed water (storm water); 2 - storm water with addition of sodium chloride, 3000 ppm; 3 - storm water with addition of sodium chloride, $6000 \mathrm{ppm}$.

dependencies of $\mathrm{C} / \mathrm{C}_{\text {req }}$ ratios on recovery. The growth of feed water salinity (TDS) decrease membrane rejection characteristics. Figure 15 shows results of experiments aimed at investigation of feed water TDS influence on oil concentration behavior in the product water after treatment of car wash wastewater with different salinities. With TDS growth concentrations of oil in the product water also increase.

Figure 16 shows results of experimental data processing to predict efficiencies of oil removal depending on feed water salinity and recovery. Extrapolation of the obtained curves provides dependencies of oil concentration in product water on recovery that corresponds to required TDS level in the feed water.

Throughout its concentration cycle in membrane unit.

The obtained results are used to determine $\mathrm{RO}$ operational conditions: membrane type, required recovery, pressure etc.

\section{RESULTS AND DISCUSSIONS. PRINCIPLES OF RATIONAL WATER MANAGEMENT IN LOCAL UTILITES USING DEVELOPED RO TECHNIQES.}

The modern concept of rational water resources management requires the development of new and efficient techniques for the treatment and reuse of wastewater. The authors developed an approach to solve the problem of environmental pollution.

This approach results in the development of local water management programs. The efficiency of the RO techniques depends on wastewater salinity. The data presented in Figure $\mathbf{8}$ and Table 2 indicate that the efficiency of RO (the possibility of reducing concentrate flow to $1 \%$ ) is dependent on the feed water TDS. To reduce wastewater TDS, RO membrane units should be used to produce potable water (that ultimately goes to the sewer) and to produce boiler feed water for

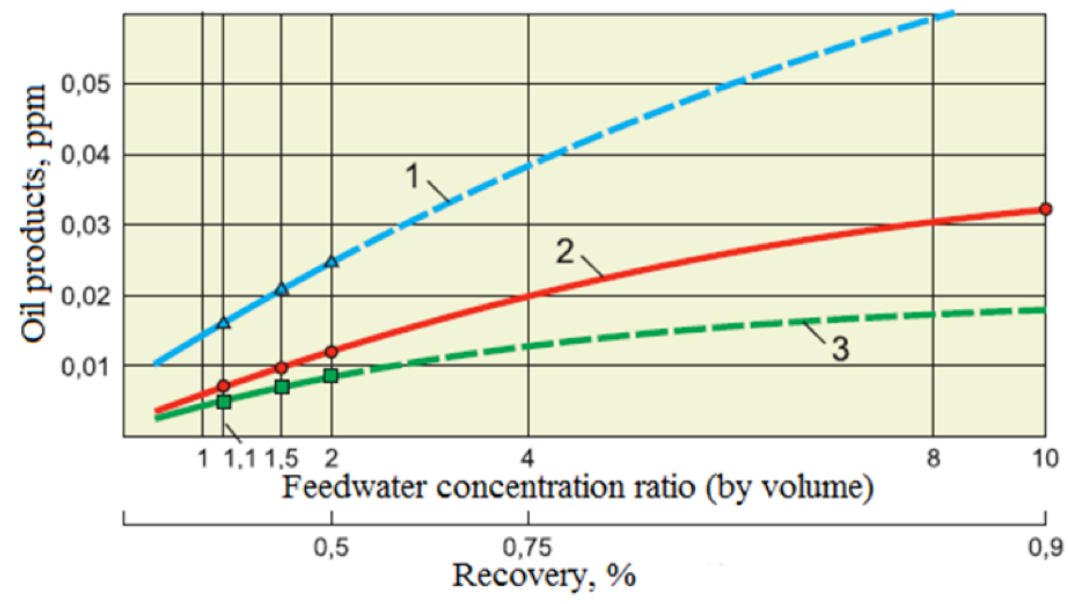

Figure 16: Oil concentrations in product water versus recovery and concentration factor for different TDS values of feed water. Feed water TDS: 1 - 1500 ppm; 2 - 774 ppm; 3 - 300 ppm. 
heating systems (replacing ion exchange softeners conventionally used for water softening) to avoid discharge of regeneration solutions to the sewer. The purified wastewater can be used for garden irrigation, washing cars, and to feed cooling/heating systems. Storm water that contains oil and surfactants is also purified by similar $\mathrm{RO}$ techniques. This treatment and concentrate utilization is facilitated by low TDS of storm water.

To decrease groundwater consumption and wastewater discharge, wastewater effluents can be treated by a local $\mathrm{RO}$ plant to provide quality technical water that can be reused for boiler feed, car washing, plant watering. To reduce concentrate flow value, membrane RO units should be also used for drinking water production. Membrane units produce water with decreased TDS, iron and hardness concentrations. Therefore, total TDS of wastewater can be significantly reduced through the use of $\mathrm{RO}$, and concentrate discharge could be minimized. With the average unit water consumption value assumed at 200-250 liter per person daily, wastewater after shower and toilet use increased TDS by only 40-50 ppm. If supplied water has TDS value of $100 \mathrm{ppm}$ or less, this water could be easily treated by $R O$ and $R O$ concentrate could be easily utilized and discharged as sludge humidity. Figures 17 and 18 show water flow distribution: a flow diagram of water supply and wastewater treatment facilities developed for a small utility of 200-300 residents.

There is no place to discharge wastewater, and the suggested techniques enable to completely reuse it for local industrial needs such as: boiler feed, heating, cooling, plant watering.

Membrane facilities tailored with "open channel" modules can be used for multi-purpose needs as they can treat wastewater and well water. Thus, local water utilities can use the same RO unit for technical water production (for boiler feed, heating and cooling) using both well water source and collected storm water.

This provides an efficient return of investment in storm water treatment and reuse.

A strategy of local utilities water management is developed that is based on the use of membrane facilities both for water supply and wastewater treatment/reuse. Membrane units provide efficient product water quality when treating both municipal and storm water to purify and reuse it for technical
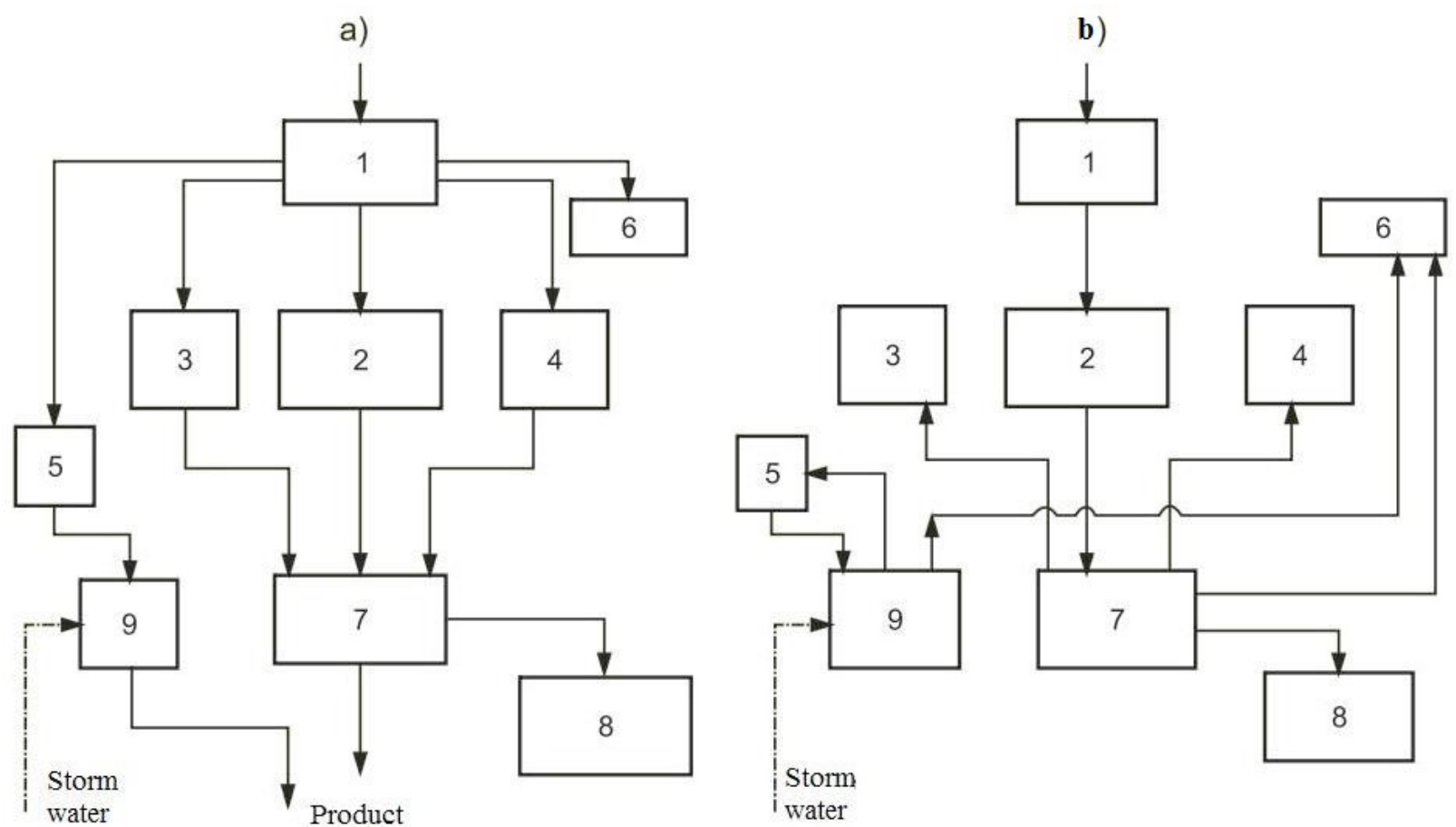

Figure 17: A balance flow diagram of water supply and wastewater treatment at a local utility: existing scheme (a) and proposed scheme using membrane techniques (b).

1- water treatment plant (a - iron removal; b -RO plant); 2 - facilities buildings; 3 - compressor pump station; 4 - boilers; 5 - car washing ground; 6 - plant watering station; 7 - wastewater treatment plant; 8 - sludge beds; 9 - storm water treatment and car washing effluents treatment station. 


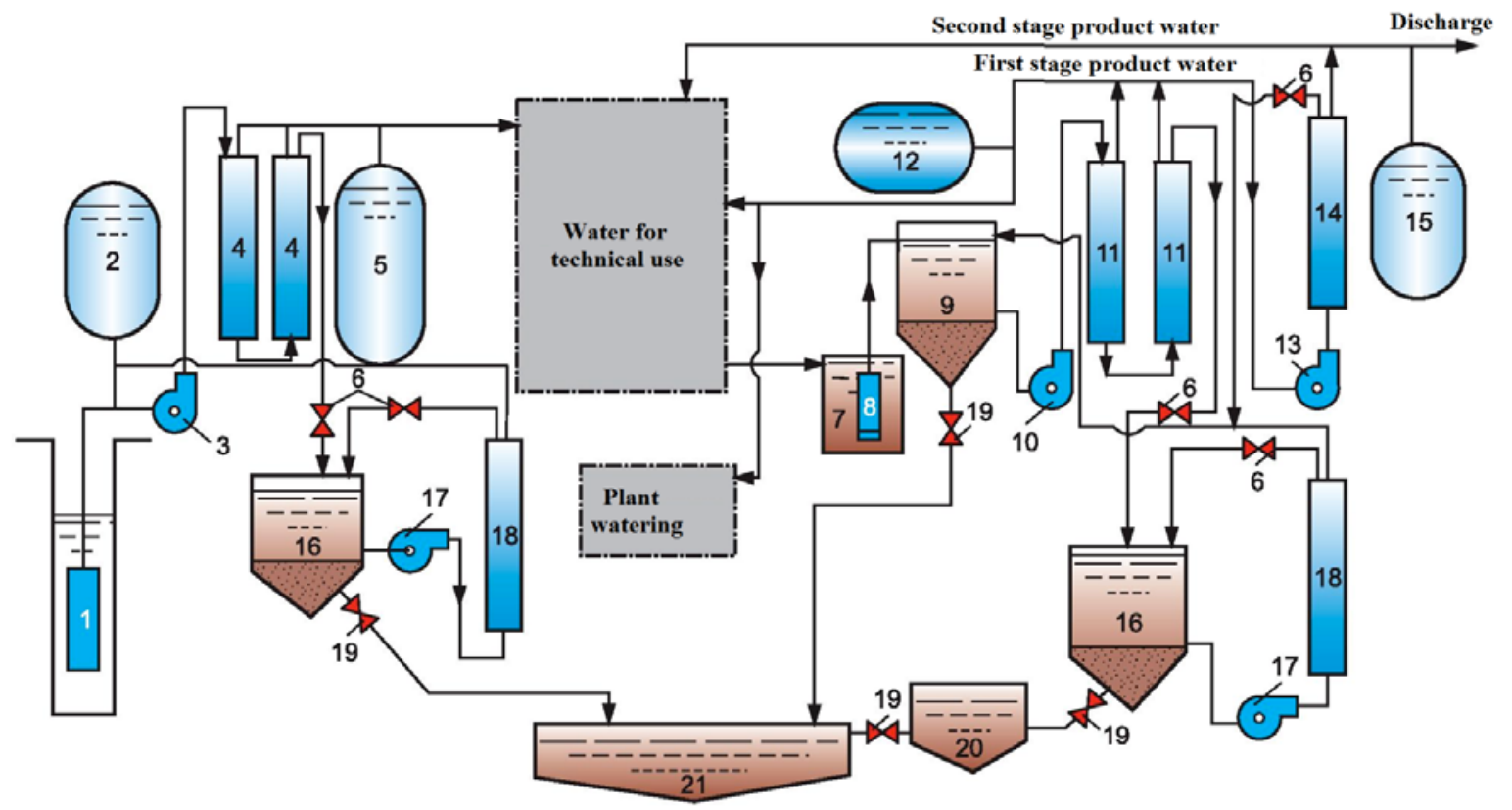

Figure 18: Flow diagram of membrane techniques used for drinking water production, wastewater treatment and reuse. 1 - well pump; 2 - well water pressure tank; 3 - membrane unit pump; 4 - membrane modules; 5 - product water pressure tank; 6 - pressure gauges; 7 - wastewater collection tank; 8 - wastewater feed pump; 9 - first stage RO concentrate sedimentation tank; 10 - first stage RO pressure pump; 11 - first stage RO membrane modules; 12 - first stage RO pressure tank; 13 - second stage RO pump; 14 - second stage RO membrane modules; 15 - second stage RO pressure tank; 16 second stage RO concentrate sedimentation tank; 17 - concentrate flow reduction unit pump; 18 - concentrate flow reduction unit membrane module; 19 - sludge disposal valve; 20 - septic tank; 21 - sludge bed.

purposes: for boiler feed and heating, for cooling systems and garden pouring.

To reduce the amount of wet sludge discharge, wastewater ionic composition should also be controlled using RO to produce low TDS product water for drinking and domestic needs.

To facilitate treatment of wastewater, small size local membrane units are used at the points where "sources of contamination" are detected: ion exchange regeneration solution discharges, storm water collected from car parking lots, gas stations and gas storage tanks.

\section{CONCLUSIONS}

To treat wastewater, specially designed membrane "open channel" modules are used that do not possess "dead areas" that cause fouling.

The main principles of high recovery maintenance are ensured by concentration of the feed water in circulation mode by $50-100$ times by volume. Concentrate volume constitutes no more than $0,5-1 \%$ of the initial feed water volume and is withdrawn from the system together with a wet sludge as a sludge moisture.
The present report demonstrates the design of "integrated" water management using the developed $\mathrm{RO}$ systems for water supply and wastewater reuse as an example of advanced, ecologically-safe water treatment. Local utilities and privately-held industrial sites are encouraged to reuse wastewater and reduce freshwater intake, thereby promoting rational water management and reducing environmental pollution.

\section{REFERENCES}

[1] Gagliardu P, Aghan S. Water reclamation with membrane bioreactors, Proc. of the conf. on Membranes, Paris, Desalination publications, L'Aquila, Italy October 2000; Vol. 2: pp. 105-112.

[2] Ahn K-H, et al. Retrofitting municipal sewage treatment plants using an innovative membrane bioreactor system. Desalination 1999; 124: 279-286. http://dx.doi.org/10.1016/S0011-9164(99)00113-7

[3] Ahn K-H, et al. Performance comparison of a direct membrane bioreactor for domestic wastewater treatment and water reuse, Proc. of the conf. on Membranes, Paris, Desalination publications, L'Aquila, Italy October 2000; Vol. 2: pp. 313-322.

[4] Losier J, Fernandez A. Using a membrane bioreactor/reverse osmosis system for indirect potable reuse, Proc. of the conf. on Membranes, Paris, Desalination publications, L'Aquila, Italy October 2000; Vol. 2: pp. 297-311.

[5] Duin $O$, Wessels $P$, et al. Direct nanofiltration or ultrafiltration at WWTP effluent. Proc. of the conf. on Membranes, Paris, Desalination publications, L'Aquila, Italy October 2000; Vol. 2: pp. 105-112. 
[6] Abdel-Javad M, Ebrahim S, et al. Advanced technologies for municipal wastewater purification: technical and economic assessment. Desalination 1999; 124: 251-261. http://dx.doi.org/10.1016/S0011-9164(99)00110-1

[7] del Pino MP, Durham B. Wastewater reuse through dualmembrane processes: opportunities for sustainable water resources. Desalination 1999; 124: 271-277. http://dx.doi.org/10.1016/S0011-9164(99)00112-5

[8] Pervov A. Scale formation prognosis and cleaning procedure schedules in reverse osmosis operation. Desalination 1991; 83: $77-118$

http://dx.doi.org/10.1016/0011-9164(91)85087-B

[9] Pervov A, Andrianov A. Application of membranes to treat wastewater for its recycling and reuse: new considerations to reduce fouling and increase recovery up to 99 per cent. Desalination Water Treatment 2011; 35: 2-9.
[10] Riddle RA. Open channel ultrafiltration for reverse osmosis pretreatment. IDA World Conference on Desalination and Water Reuse. Washington DC. Pretreatment and Fouling August 25-29, 1991.

[11] Bian R, Yamamoto $K$, Watahabe $Y$. The effect of shear rate on controlling the concentration polarization and membrane fouling. Proceedings of the Conf. on Membranes in Drinking and Industrial Water Production, Paris, France, 3-6 October 2000, Vol. 1: pp. 421-432.

[12] ITT PCl Membranes - Membrane Technology- tubular membranes - micro-, ultra-, nanofiltration, reverse osmosis, http: // www.pcimembranes.eu/ (accessed 7 November 2010).

[13] Futselaar H, Schoneville H, Meer W. Direct capillary nanofiltration for surface water. Desalination 2003; 157: 135136.

http://dx.doi.org/10.1016/S0011-9164(03)00392-8

DOI: http://dx.doi.org/10.6000/1929-6037.2014.03.01.2

(c) 2014 Pervov and Matveev; Licensee Lifescience Global.

This is an open access article licensed under the terms of the Creative Commons Attribution Non-Commercial License (http://creativecommons.org/licenses/by-nc/3.0/) which permits unrestricted, non-commercial use, distribution and reproduction in any medium, provided the work is properly cited. 